Review Article

\title{
A Short Review on Synthesis, Characterization, and Applications of Zeolites
}

\author{
Tessema Derbe $\left(\mathbb{D},{ }^{1}\right.$ Shewaye Temesgen, ${ }^{1}$ and Mamaru Bitew ${ }^{2}$ \\ ${ }^{1}$ Department of Chemistry, Wachemo University, P.O. Box 667, Hossana, Ethiopia \\ ${ }^{2}$ Department of Chemistry, Debre Markos University, P.O. Box 269, Debre Markos, Ethiopia
}

Correspondence should be addressed to Tessema Derbe; benyamderbe@gmail.com

Received 5 December 2020; Revised 17 August 2021; Accepted 25 August 2021; Published 28 September 2021

Academic Editor: Michele Fedel

Copyright $\left({ }_{0} 2021\right.$ Tessema Derbe et al. This is an open access article distributed under the Creative Commons Attribution License, which permits unrestricted use, distribution, and reproduction in any medium, provided the original work is properly cited.

The review emphasizes on synthesis, characterization, and application of zeolite. Zeolite is a hydrated aluminosilicate having a tetrahedral structural framework; it contains channels and cages which are occupied by exchangeable active metal ions and water molecules. Zeolite was synthesized through different synthesis methods, particularly, hydrothermal and green synthesis methods. The review also has tried to address the structure of zeolite such as morphology, functional group, and particle size using different characterization methods as reported via different authors. The characterization results verify that zeolite shows many unique properties such as uniform pore size, acidic properties, thermal stability, mobile extra cation, hydrophilicity, and hydrophobicity. These lead to a number of applications in catalysis, water purification, adsorption, and agriculture.

\section{Introduction}

Zeolites are hydrated aluminosilicate that is made from tetrahedral alumina $\left(\mathrm{AlO}_{4}{ }^{5-}\right)$ and silica $\left(\mathrm{SiO}_{4}{ }^{4-}\right)$ through interlinkage of oxygen atoms $[1,2]$. The term zeolite is derived from Greek words "Zeo" and Lithos" [3-5] which means boil and stone, respectively; zeolites have high ability of absorbing water and releasing it when they get heated [4]. They have an open void with 3D crystal structure having aluminum, silicon, and oxygen coordination with active metals [5]. Zeolites are composed of central atoms (Al, Si or P), and terminal oxygen atom in tetrahedral structure to form primary building blocks (as indicated in the left side of Figure 1); they can also form secondary building blocks by bridging through oxygen-oxygen atoms to form rings, prisms, and various sizes (as it is seen at the right side in Figure 1).

Zeolites are composed of an elementary structure of an aluminosilicate framework, which comprises a tetrahedral arrangement of silicon ion $\left(\mathrm{Si}^{4+}\right)$ and aluminum ion $\left(\mathrm{Al}^{3+}\right)$ that are surrounded by four oxygen anions $\left(\mathrm{O}^{2-}\right)[2,4,7]$. Each oxygen ion within $\mathrm{Si}-\mathrm{O}$ and $\mathrm{Al}-\mathrm{O}$ bonds connects with two cations and which are shared between two tetrahedron structures $[6,8]$. This results in the tetravalent electroneutral $\mathrm{Si}$ in $\mathrm{SiO}_{4 / 2}$ and the trivalent negatively charged $\mathrm{Al}$ in $\mathrm{AlO}_{4 / 2}$ [9]. The negative charge and the pores of zeolites can be occupied by group IA or IIA metal ions and water molecule as it is denoted via the general formula, $\mathrm{Mx} / \mathrm{n}$ $\left\{\left(\mathrm{Al}_{2} \mathrm{O}\right)_{\mathrm{x}}\left(\mathrm{SiO}_{2}\right)_{\mathrm{y}} \cdot \mathrm{zH}_{2} \mathrm{O}\right\}$ [10-12], where $M$ represents an alkali or alkaline Earth cation, $n$ represents the valence of the cation, $z$ is the number of water molecules per unit cell, and $x$ and $y$ are the total numbers of tetrahedral per a unit cell.

Zeolites can be classified into two broad groups, namely, natural and synthetic zeolites $[8,12,13]$. Natural zeolites are mostly formed from volcanic and sedimentary rocks such as chabazite, clinoptilolite, and mordenite [13]. On the contrary, synthetic zeolites are prepared through heating of China clay, feldspar, soda ash, and other sources $[13,14]$. There are also different types of synthetic zeolites such as zeolite A, zeolite X, zeolite $\mathrm{Y}$, and zeolite $\mathrm{P}$, which can be synthesized from different resources $[15,16]$. Zeolites A, zeolites $\mathrm{X}$, and zeolite $\mathrm{Y}$ consist of a cubo-octahedral (i.e., p-cages) having $\mathrm{SiO}_{4}{ }^{-}$and $\mathrm{AlO}_{4}{ }^{-}$tetrahedral at each corners of the framework [14, 17]. Zeolites $\mathrm{X}$ and $\mathrm{Y}$ are well known for their remarkable stability and rigid structure with large void space $[6,15]$. This group of 


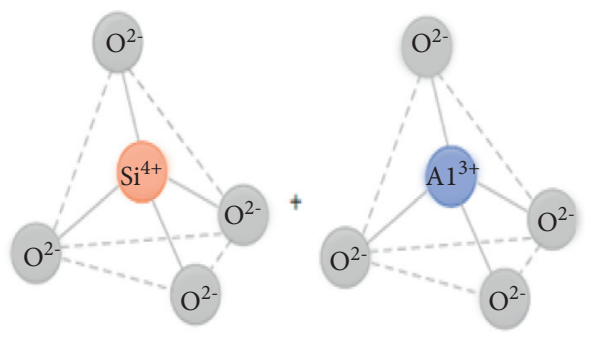

Pramiry build unit of Zeolites
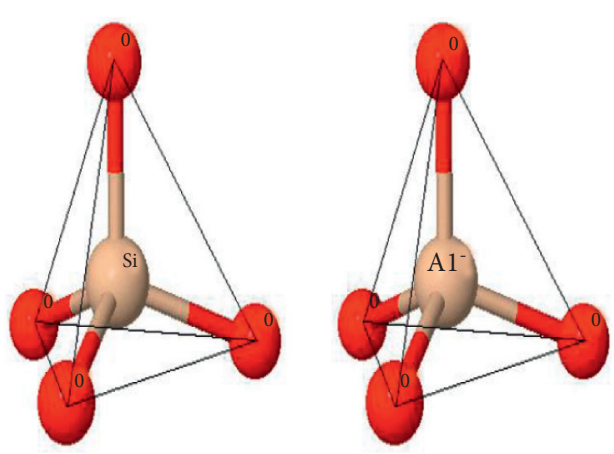

The PBUs are the $\left(\mathrm{SiO}_{4}\right)^{4-}$ and $\left(\mathrm{AlO}_{4}\right)^{5-}$

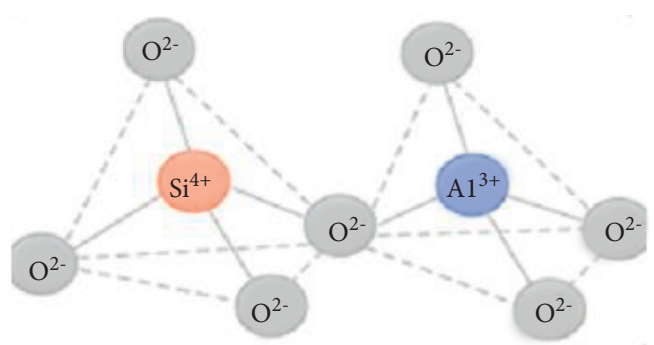

Secondary building unit of Zeolites

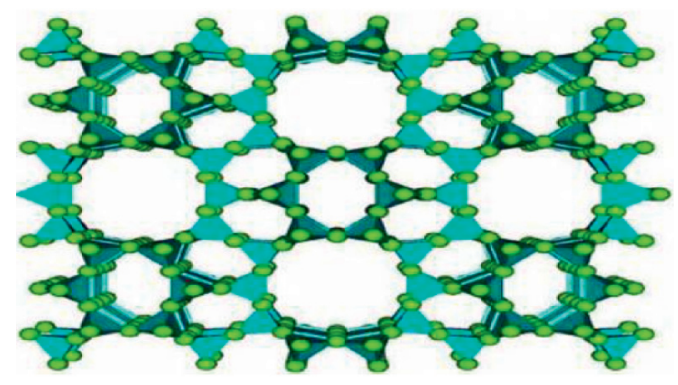

The PBU is combined by sharing oxygen atom with adjacent tetrahedral to form the SBUs. SBUs might be single rings, double rings, polyhedra or more complex units.

Figure 1: Primary and secondary building units of zeolites adopted from the work of Moshoeshoe et al. [4] and Mgbemere and Ekpe [6].

zeolites plays an important role in gasoline production as catalytic cracking of gas oil $[18,19]$.

The other familiar zeolite is Zeolite A, which is synthesized from sodium aluminosilicate usually referred as zeolite $\mathrm{NaA}$ or zeolite $4 \mathrm{~A}$, represented by the formula $\mathrm{Na}_{12}$ $\left(\mathrm{AlO}_{2}\right)_{12}\left(\mathrm{SiO}_{2}\right)_{12} \cdot 27 \mathrm{H}_{2} \mathrm{O}[14,17]$. It is the type of synthetic zeolite that is used in detergent production for treatment of hard water. It is also used to substitute sodium tripolyphosphate which is an environmentally unfriendly detergent product [15]. Furthermore, zeolite 4A has large ion exchange capacity with an average particle size ranged from 4 to $10 \mu \mathrm{m}$, which prevents graying and dye transfer from one cloth to another cloth during washing in laundry $[18,19]$.

Currently, zeolites were synthesized from different natural sources, such as clay, kaolin, fly ash, coal, natural oxide, bauxite, feldspar, activated carbon, and other silica sources [19-21]. Zeolites, synthesized from natural sources, have highly porous cavities in their structure, high ionic exchange capacity, large specific surface area, low cost, and hydrophilic in nature $[3,18,22]$. For instance, the cost comparison of obtaining a silica and alumina source from a chemical feedstock and kaolin/metakaolin has been carried out, and the result shows that zeolite A synthesized from clay has a comparative cost advantage of $15 \%$ over a commercial chemical such as sodium silicate $[1,3,15]$. Moreover, these zeolites are cheaper and more abundant and are employed as the sole source of silica and alumina as compared to synthetic zeolites [23, 24].

Zeolites, both natural and synthetic, have huge applications in industrial, agricultural, and biomedical processes $[25,26]$. Many researchers have turned their attention to synthesis, characterization, and surface modification of zeolites along with their applications. For instance, Olaremu, et al. [1] encapsulated the composition of zeolites using active metals mainly group alkali and alkali Earth metals to relive the variation of Al to Si ratio. Wang et al. [10] synthesized Cr-doped $\mathrm{TiO}_{2}$ supported zeolites in order to improve their structures, pore size, channels and absorption ability during photocatalytic activities [13, 27, 28]. Nyankson et al. [12] also reported Zn (II) supported zeolite as the Zn-zeolite framework that generates a secondary pore; the secondary pore results larger surface area and has the ability to removal dyes, heavy metals, pesticides, and other pollutants from water [13,29]. Therefore, this review explores the synthesis, characterization, and applications of zeolite $[13,22,29]$.

\section{Synthesis Methods of Zeolites}

The synthesis approach of zeolites can be divided into two main assembles on the basis of secondary porous formation, namely, bottom-up and top-down approaches [14]. The bottom-up approach includes hard templating, soft templating, and nontemplating processes. In this approach, the secondary porous will be created during templates' stage; modification is achieved under synthesis conditions (nontemplating methods). It is a direct and one-step approach that results in a sequential rotational intergrowth of zeolite frameworks $[4,14]$. In the "top-down" approach, the secondary porous is created at the post-synthesis stage $[4,14,18]$. This approach follows demetallation, delamination, and recrystallization processes [14, 17, 19]. 
2.1. Hydrothermal Synthesis Method. Hydrothermal synthesis method of zeolite consists of two stages: the initial stage, formation of hydrated aluminosilicate gel, and the crystallization stage $[4,12]$. The crystallization stage also consists of four steps: (i) condensation of polysilicate and aluminate anions, (ii) nucleation of zeolites, (iii) growth of nuclei, and (iv) crystal growth of zeolites, as shown in Figure $2[18,19,25]$.

In short, the synthesis procedures are depicted in Figure 2; amorphous aluminum and silicate were transformed into a sol gel or clear solution through dissolving with water under alkaline or acidic condition (I). The sol-gel mixture was heated in an autoclave until the crystal forms preordered subunit (II). A small crystal of zeolite having long-range order was formed during the nucleation stage (III). Finally, well-grown crystalline zeolites were formed (IV).

Conventionally, the hydrothermal method involves crystallization of aluminosilicate gels (a mixture of aluminate and silica solution in the presence of alkali hydroxides and organic bases) $[23,25]$. Nonetheless, the synthetic type and nature of zeolite are highly affected by different factors [23] such as composition of silica and alumina, nature of precursors and their pretreatment [28], temperature $[29,30]$, reaction time, and $\mathrm{pH}$ of the reaction mixture [26].

Nyankson, et al. [12] synthesized zinc-exchanged zeolite A (Zn-Zeolite A) from alumina and silica-based deposits (kaolin, bauxite, silica, and feldspar) sampled from three regions in Ghana through the hydrothermal method. The authors concluded that the hydrothermal method required high crystallization time around 7:00 hrs for the formation of zeolite phases [12, 23, 28]. However, the hydrothermal synthesis method used organic templates and high pressure. Besides, this method needs high pressure, has low efficacy, has high potential of polluting, and emits high greenhouse gases during combustion of organic templates [14, 30]. It also has low concentrations of silicon and aluminum, which requires multiple recycling treatments and releases excessive residual solution into the environments $[14,30,31]$. The authors also did not compare other zeolite synthesis methods such as the dry gel method, the vapor-phase transformation method, or the solvent-free method.

2.2. Green Synthesis Methods. The hydrothermal synthesis method produces substantial quantity of wastes and generates carbon dioxide and nitrogen-containing gases [14]. Therefore, an alternative synthesis approaches had been designed to overcome such challenges. Thus, newly developed approaches are used to increase the crystallization rate, develop continuous-flow synthesis, simplify post-treatment of a residual solution after synthesis, and enhance the production yield $[14,28,30]$. These synthesis approaches are generally noted as green synthesis of zeolite [16, 20, 22].

The ionothermal synthesis method is characterized using ionic solvent and template to avoid high pressure, which is caused by water vapor $[18,30]$. In 2004, Wang et al. reported the first synthesis of aluminophosphate and silico-aluminophosphate zeolites through the ionothermal method [10]. This resulted in high efficient and high surface area zeolite.
The other green synthesis method is solid-state or quasisolid-state synthesis $[17,18]$. Typically, quasi-solid-state synthesis method is a dry gel conversion approach that was developed by different authors such as Deng et al. [17], using a bit of solvent [17]. Xiao et al. [31] also reported the solidstate synthesis method in which the initial solid raw material is grounded and mixed without adding any solvent [31].

The microwave-assisted method is characterized by having mild reaction conditions and high crystallization rate $[14,30,31]$. This method has been developed to promote the nucleation rate of zeolites through increasing of the crystallization rate [31-33]. Omisanya et al. [2] synthesized zeolite A from Kankara kaolin under microwave conditions using adsorbent in a solar refrigerator. The continuous-flow synthesis method is characterized by a complete crystallization within seconds or minutes due to the large heat transfer coefficient that carried out in a tubular reactor $[13,18]$. Pan et al. [14] reported the crystallization rate of zeolite Socony-Socony Mobil-5 (ZSM-5) from amorphous aluminosilicate gel within a minute. The authors verified that this synthesis method provides great potential for facilitating the mass production of industrial zeolites $[2,14,16]$. The other synthesis method is the solvothermal method that involves a solvent such as polar solvents and nonpolar solvents [14, 30, 31]. Xiao et al. [31] synthesized faujasite zeolite from silica and pearlite. Both the silica and the pearlite were mixed in sodium hydroxide solution, and commercial aluminum-hydroxide was dissolved in sodium hydroxide to produce synthesized gel. Crystallization of the produced gel was done at a temperature of $90^{\circ} \mathrm{C}$ for $120 \mathrm{hrs}$; then, mixed phases of zeolite $\mathrm{Y}$, zeolite $\mathrm{P}$, and gmelinite were produced [2, 31].

Odebunmi et al. [1] synthesized zeolite from kaolin clay in Erusu Akoko south western Nigeria. The kaolin clay was converted to metakaolin at $600^{\circ} \mathrm{C}$ and then leached with sulfuric acid to achieve the required silica-alumina ratio $[1,14]$. An alkaline fusion was carried out to transform the metakaolin into Zeolites $\mathrm{Y}, \mathrm{X}$, and $\mathrm{P}[1,10,19]$. In the fusion process, kaolin is thermally activated by the addition of sodium hydroxide to form an active $\mathrm{Al}$ and $\mathrm{Si}$ species $[14,19]$. These species tend to react with each other followed by reorganizing to form a ring-like structure that used as basic units for the zeolite framework. The authors deduced zeolites were successfully synthesized from local source such as clay through alkaline treatment of its metakaolin under the solvothermal process, which is important in the petroleum industry as a catalyst and wastewater treatment as an adsorbent $[1,23,34]$. Nevertheless, authors did not introduce secondary pores (meso- or macropores) to reduce the zeolite crystal size to the nanometer scale to give hierarchical and nanosized zeolites and enhance diffusion limit of bulky molecules into the pores and out of the pores.

Luo et al. [25] synthesized sodalite from alkali-activated coal fly ash through the hydrothermal process for the removal of lead ions and realized the effect of temperature, $\mathrm{pH}$, initial concentration, and adsorption time during the adsorption process $[16,25]$. However, still the authors did not realize the effects of competing metal ion (more active metals than lead ion). Deng et al. [17] also synthesized zeolite 


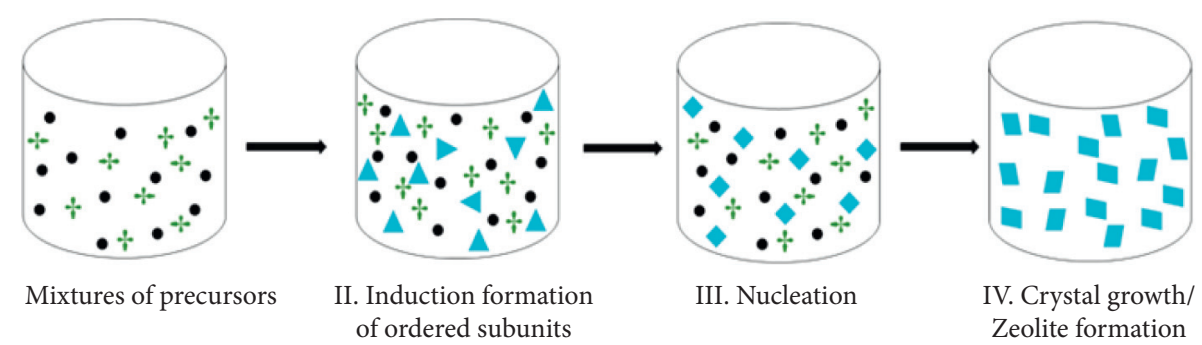

FIgUre 2: Steps in zeolite synthesis adopted from Omisanya et al. [2].

through hydrothermal followed by fusion methods $[14,16]$ from municipal solid waste fly ash (MSWFA) and showed that there is no significant difference on the produced zeolite as compared to the zeolite synthesized through the two methods. Nevertheless, the hydrothermal method consumed high energy and was time-consuming during zeolite synthesis from MSWFA [17, 23].

Wang and Peng [35] reported Cr-supported and $\mathrm{TiO}_{2}{ }^{-}$ doped photocatalytic natural zeolites through displacing of $\mathrm{TiO}_{2}$ lattice with $\mathrm{Ti}^{4+}$ sites due to the close ionic radius of $\mathrm{Ti}^{4+}$ and $\mathrm{Cr}^{3+}[10]$. They bring enhancement to the binding force of $\mathrm{Cr} / \mathrm{O} / \mathrm{Ti}$ through the increment of calcination temperature. This improves the photocatalytic activity of the synthesized zeolites $[10,25]$. The authors inferred that the gab energy is significantly reduced in $\mathrm{Cr} / \mathrm{TiO}_{2}$-doped zeolite than the undoped one. Thus, doped $\mathrm{Cr} / \mathrm{TiO}_{2}$ zeolite exhibits higher de-colorization and photocatalyst activity than the undoped $\mathrm{TiO}_{2}$ zeolite $[10,17,31]$.

Ruíz-Baltazar et al. [18] synthesized zeolite from natural precursors such as clinoptilolite, mordenite, and feldspars and further encapsulated with iron to increase adsorption capacity of zeolite as iron nanoparticles [18]. The authors inferred that lower concentration of iron nanoparticles have greater interaction with the surface area of the prepared zeolite $[18,20]$. However, further increments of the iron concentration diminished adsorption of processes due to a saturation of iron on the surface of the zeolite. The authors verified optimum concentration of iron which has higher adsorption of pollutants; the result agrees with the Lagergren model $[18,19,31]$.

Sudiyarmanto [36] also synthesized natural zeolite through the wet impregnation method using hydrogen chloride $(\mathrm{HCl})$ solution and metal catalyst $[36,37]$. The authors successfully prepared $\mathrm{Ni}$-based natural zeolite $(\mathrm{Ni} /$ ZAB) through the wet impregnation method $[13,36]$. The prepared zeolite showed good hydrogenation reaction with citronellol and high adsorption activity for 3, 7-dimethyl-1octanol compound. Nevertheless, the catalytic performance of the prepared catalyst varies with temperature and pressure towards yield and selectivity of 3, 7-dimethyl-1-octanol production [36]. Moreover, authors did not explain the catalytic activities of zeolites in comparison with metalencapsulated zeolite or presence of extra pores in zeolite. Yongquan et al. [38] synthesized $\mathrm{NaY}$ zeolite in a rotating packed bed (RPB); authors verified zeolites $\mathrm{NaY}$ in RPB which shows short reaction time, small particle size, high catalytic performance, and feasible industrial application than zeolite $\mathrm{NaY}$ synthesized through conventional synthesis methods.

Hongwei et al. [39] synthesized nanocrystals' templatefree zeolites (zeolite $\mathrm{Y}$ and $\mathrm{X}$ ) using reverse microemulsionmicrowave method in comparison with the template synthesis method. The result revealed that the template approach is normally carried out by calcination, which leads to irreversible aggregation of the nanocrystals; the use of the template in the synthesis tends to change the $\mathrm{Si} / \mathrm{Al}$ ratio of the final products that could drastically affect their applications. However, template-free zeolite synthesis has the advantages of short reaction time, producing small particles with a narrow size distribution and high purity.

Sajo et al. [40] synthesized zeolitic mesoporous materials by dry gel conversion under controlled humidity; the dry gel conversion (DGC) method, sometimes called the vaporphase transport method, is typically carried out in a reactor where a porous support stands above a reservoir of water or other volatile liquids. The authors deduced that the DGC method generates less waste and requires less reactor volume and is very effective if the product is to be made into selfbonded pellets or membranes than the conventional hydrothermal method. Naser Azizi et al. [41] synthesized template-free zeolite $\mathrm{P}$ and its phase transformation to two types of high crystalline zeolites $\mathrm{Y}$ and analcime with changing crystallization temperature $\left(80-160^{\circ} \mathrm{C}\right)$. They also observed the effect of $\mathrm{Si} / \mathrm{Al}$ ratios and crystallization times on transformed zeolites because the $\mathrm{Si} / \mathrm{Al}$ ratios have a great influence in the phase transformation during template-free synthesis of zeolite $\mathrm{P}$.

Ghadamnan et al. [42] compared the microporous cavities and channels of zeolites at nanoparticles' scale for application of ion exchange and catalysis through encapsulation of cations, complexes, and metals. Encapsulation of zeolite can provide a strict control of the nanoparticle size as well as a limitation of aggregation at high temperature. The authors also summarized the hierarchical structures or unusual morphologies of zeolites as well as perspectives in the design of zeolite-containing metal nanoparticles, which differ from traditional materials by the originality of the synthesis method or the morphology of the support. Yuanyuan et al. [43] presented green fabrication of hierarchical zeolites from natural minerals through a versatile mesoscale depolymerisation-reorganisation strategy. This hierarchical zeolite synthesis method offers an effective solution to overcome the drawbacks of conventional zeolites in catalytic applications zeolites [44]. 
Nowadays, a tremendous progress has been made in zeolite synthesis for sustaining the synthesis factors such as sources of silica and alumina, mobile ions of alkali/alkaline Earth metals, mineralizing agents of hydroxide/fluoride, concentration of gel, and conditions of synthesis processing. This leads to the development of variety of zeolite-templating approaches and the discovery of a novel synthesizing methods of zeolite such as the dry gel method, vapor-phase transformation method, solvent-free method, and templatefree method. Besides, researchers find a cheaper zeolite source [15] such as clay minerals, natural zeolites, coal ashes, municipal solid waste, incineration ashes, and industrial slags as a starting material for synthesizing of zeolite using those novel synthesis methods [31].

In perspective, the hydrothermal method causes greenhouse gas emissions' problem and high energy consumption during calcination, recycling reagents in the residual solution and results in pollution. On the contrary, the synthetic route via solid-state or quasi-solid-state synthesis (i.e., both template-free and solvent-free routes) appears to be a sustainable choice. However, the mass production of zeolites followed by solvent-free (solid-state synthesis) (quasi-solid-state synthesis) routes is still challenging because of the difficulty of the heat and mass transfer involving solid-state reactions. Continuous-flow synthesis and microwave-assisted synthesis methods indeed promote production efficiency by enhancing heat transfer, and their application in solid-state or quasi-solid-state synthesis is worthwhile. Microwave synthesis methods are now widely used in many zeolite syntheses due to their fast and energy efficient techniques to avoid competitive reactions in many known processes. Sol-gel synthesis process also advanced the method for zeolite synthesis due to easy encapsulation of elements (metals or metal oxides) into zeolite cavities. However, this may lead to formation of aggregation and diffusion limitations; thus, using the hierarchical approach is too important to enhance the diffusion rate and catalytic properties of zeolite.

\section{Characterization of Zeolite}

3.1. Powder X-Ray Diffraction (XRD). X-ray diffraction (XRD) is an efficient technique used to identify crystallographic structure of soiled states $[10,13,31]$. XRD is used to study the crystal structure of zeolite, crystal size of zeolites, approximate extent of heteroatom substitution, and presence of defect in zeolites [2, 4]. Melaningtyas et al. [16] synthesized $\mathrm{NaY}$ zeolite from Bayat natural zeolite and showed the effect of $\mathrm{pH}$ on $\mathrm{NaY}$ zeolite synthesis process and characterized; XRD patterns of synthesized zeolite $(\mathrm{NaY})$ at $\mathrm{pH}$ 11-13 revealed the formation of $\mathrm{NaY}$ zeolite [16]. The result was confirmed through comparison of the XRD pattern of synthesized $\mathrm{NaY}$ with $\mathrm{NaP}$ zeolite obtained from the International Zeolite Association (IZA) database (Figure 3). As the graph revealed, $\mathrm{NaY}$ zeolite was not completely formed at $\mathrm{pH} 11$ and 12, but shows some similarities to the standard $\mathrm{NaY}$ zeolite at $2 \theta$ values of $6.73^{\circ}, 10.91^{\circ}$, $23.23^{\circ}$, and $27.47^{\circ}[16,28]$. This is probably due to the presence of cations other than $\mathrm{Na}$, such as $\mathrm{K}^{+}, \mathrm{Mg}^{2+}, \mathrm{Ca}^{2+}$, and $\mathrm{Fe}^{2+}$, which were not removed during pretreatment processes [16, 45]. Zeolite $\mathrm{NaY}$ prepared at $\mathrm{pH} 11$ and 12 showed uneven baseline pattern; this indicates the presence of mixed amorphous fraction in zeolite. Nevertheless, zeolite $\mathrm{NaY}$, prepared at $\mathrm{pH} \mathrm{13,} \mathrm{showed} \mathrm{high} \mathrm{crystalline} \mathrm{structure}$ similar to that of $\mathrm{NaP}$ zeolite, as shown in Figure 3. Hence, the authors concluded that the XRD patterns revealed that the Bayat natural zeolite structure was successfully destroyed and converted into a different zeolite structure mainly zeolite $\mathrm{NaY}$. This confirms the crystalline structure and the pore uniformity, and the pore size of zeolite $\mathrm{NaY}$ is affected by $\mathrm{pH}$ values $[16,25,45]$.

3.2. Scanning Electron Microscopy (SEM). Scanning electron microscope (SEM) is used to study the surface of solids and give information about their morphology and topological via producing various signals $[12,13,27]$. Chunfeng et al. [13] studied the morphology of zeolites A and zeolite $\mathrm{X}$ using SEM and compared one another. They observed that zeolite A was formed in chamfered-edged cubes' structure while zeolite X exhibits octahedral structure (Figure 4) [10, 13].

Magdalena [45] characterized the growth rate of zeolite by comparing the one-step synthesis method with the multistep synthesis method using SEM $[10,45]$. The authors concluded that the films of synthesized zeolites through a multistep procedure show more clear morphology than the corresponding films synthesized through the one-step method [45]. Furthermore, they realized that the films synthesized by multistep are more qualified than films synthesized through one-step (Figure 5). Nevertheless, the authors did not notice the diffusion limitation and aggregation of particles during characterization.

Omisanya et al. [2] examined the morphology of prepared zeolite A from metakaolin of the kaolin sample in comparison with commercial zeolite $4 \mathrm{~A}$. The authors noticed the presence of some cubic crystal structure in prepared zeolite A along with the gel, and a plate-like structure for the kaolinite clay indicates the silica and alumina are sliding over one another [2, 16, 45]. The SEM images revealed a uniform particle size with a regular shape found in the prepared zeolite A sample. The commercial and synthesized zeolites' SEM images give a narrow distribution of particle size with an average crystal size of $<20 \mu \mathrm{m}[3,12,22]$. Nevertheless, the authors did not use the computational method to clarify structure of zeolite due to sliding of silica and alumina over one another (aggregation of particles).

Nyankson et al. [12] characterized the morphology and the textural properties of zeolites $\mathrm{A}$, magnetite nanocomposite, and zeolite/nanocomposite (zeolite $\mathrm{A} / \mathrm{Fe}_{3} \mathrm{O}_{4}$ ) using SEM analysis (Figure 6). The authors concluded that the SEN analysis confirms the presence of cubic crystals' structure of zeolite, as shown in Figure 6(a); spherical morphology of the $\mathrm{Fe}_{3} \mathrm{O}_{4}$ nanoparticles endorse the formation of the magnetite, as shown in Figure 6(b). Distortion of the original cubical occurred due to the incorporation of the magnetite nanoparticles into the zeolite framework, as shown in Figure 6(c); this indicates a bonding interaction between the zeolite and the $\mathrm{Fe}_{3} \mathrm{O}_{4}$ nanoparticles leading to 

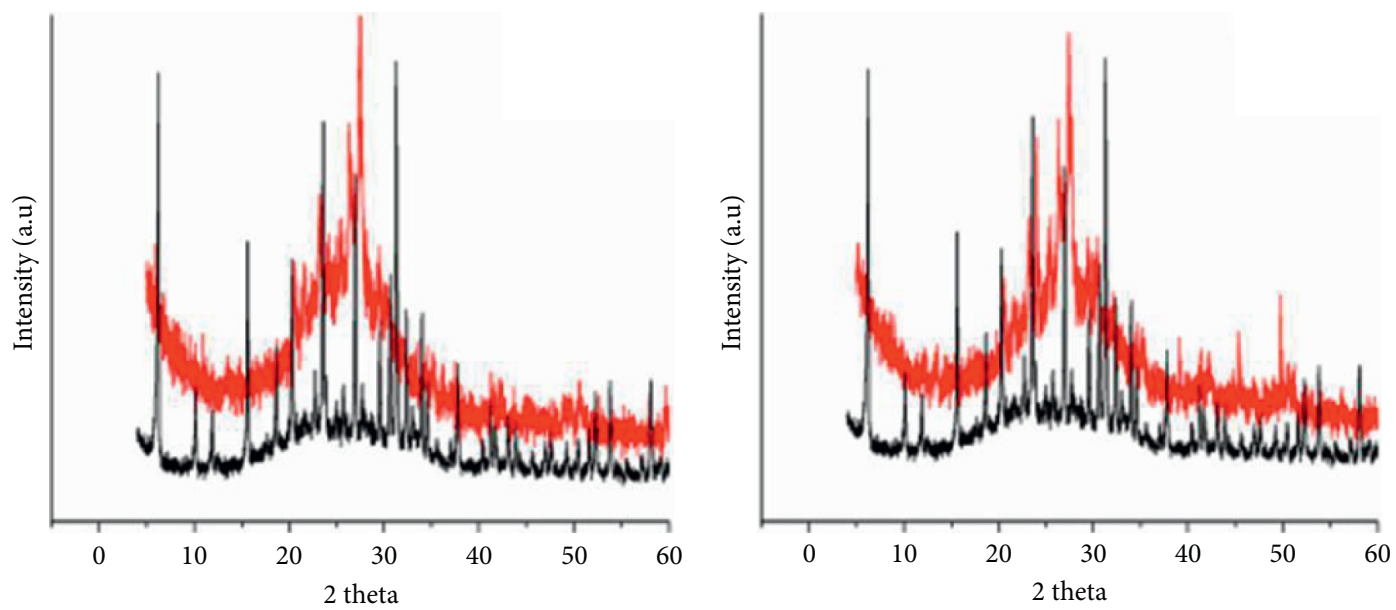

- $\mathrm{NaY}$ pH 11

- NaY pH 12

— Synthetic $\mathrm{NaY}$

- Synthetic NaY

(a)

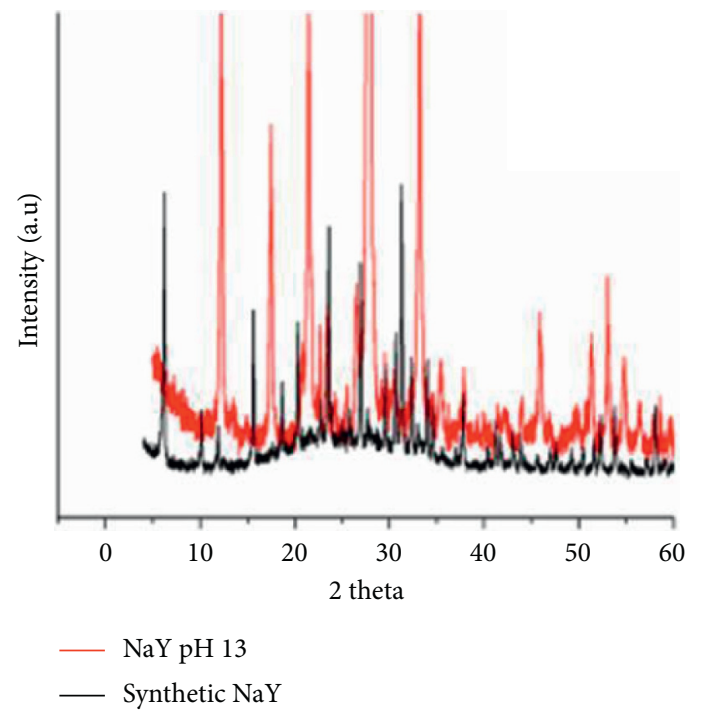

(c)

(b)

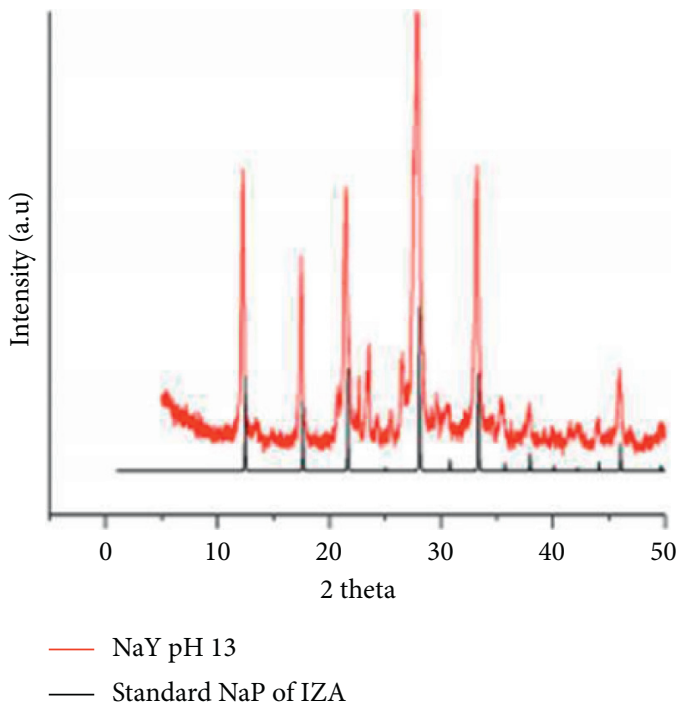

(d)

Figure 3: Comparison of NaY zeolite XRD pattern at (a) pH 11, (b) pH 12, (c) pH 13, and (d) pH 13 with that of standard NaP zeolite adopted from [16].

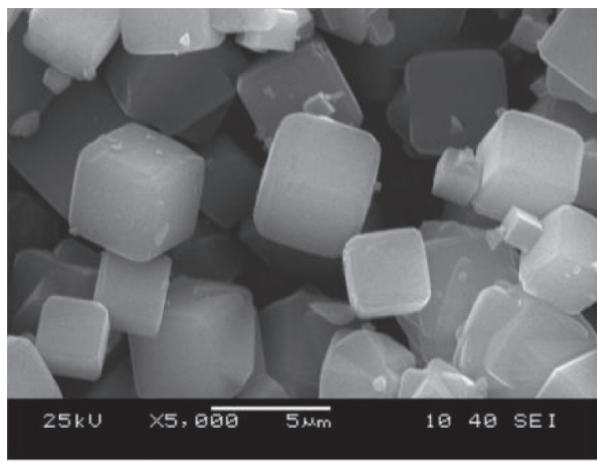

(a)

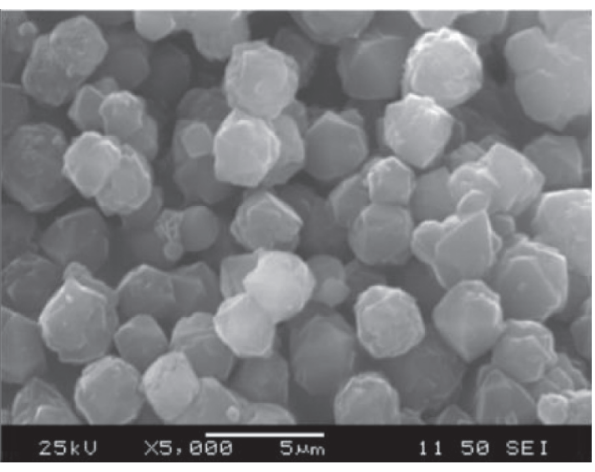

(b)

FIgURE 4: SEM images of synthetic (a) zeolite A and (b) zeolite X adopted from [13]. 

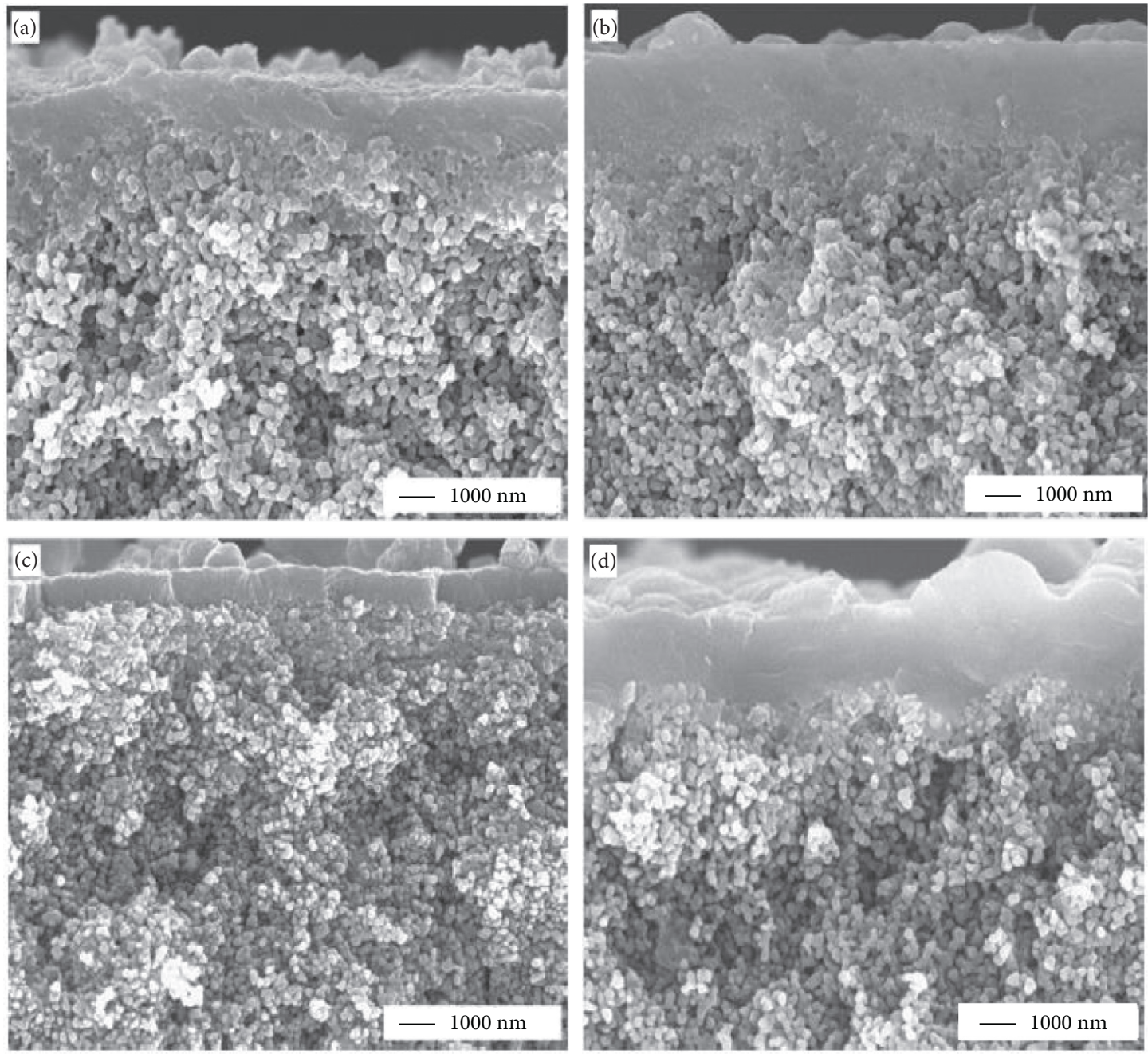

Figure 5: Side-view SEM images of membranes synthesized for 6 and 9 hours in one step (a and c) and 2 and 3 steps (b and d) at $75^{\circ} \mathrm{C}$ adopted from Magdalena [45].

morphological structural changes $[12,16]$. However, the authors did not explain the causes of distortion such as elongation during zeolite $/ \mathrm{Fe}_{3} \mathrm{O}_{4}$ nanocomposite formation.

\subsection{Fourier Transform Infrared (FTIR) Spectroscopy.} Fourier transform infrared spectroscopy (FT-IR) is used to confirm the fundamental vibrations of silica-alumina in a zeolite structure $[35,46]$. FTIR spectroscopy is used to specify the functional units of zeolites and to predict the reactions mechanism in the zeolite framework. The FTIR spectrum is also used to indicate the secondary building units which were found in the zeolite structure $[5,12]$.

Wang et al. [10] characterized and compared $\mathrm{TiO}_{2}$ and $10 \% \mathrm{Cr} / \mathrm{TiO}_{2}$ composite zeolites using FT-IR, as shown in Figure 6. The broad peak around $3437 \mathrm{~cm}^{-1}$ and $1637 \mathrm{~cm}^{-1}$ indicates the stretching and bending of $\mathrm{O}-\mathrm{H}$ bond, respectively. The peak at $1049 \mathrm{~cm}^{-1}$ indicates the Si-O-Si stretching and the weak peaks between 800 and $400 \mathrm{~cm}^{-1}$ correspond to $\mathrm{Si}-\mathrm{O}-\mathrm{Si}$ and $\mathrm{Ti}-\mathrm{O}$ bending vibration. Thus, the FT-IR peaks confirm the elemental interrelationships of the zeolite, $\mathrm{TiO}_{2} /$ zeolite, and $10 \% \mathrm{Cr} / \mathrm{TiO}_{2} /$ zeolite (Figure 7 ).
Melaningtyas et al. [16] synthesized $\mathrm{NaY}$ zeolite at $\mathrm{pH}$ values of 11,12 , and 13 with comparison of commercial $\mathrm{NaY}$ zeolite using FT-IR (Figure 8). The prepared $\mathrm{NaY}$ zeolite at $\mathrm{pH} 13$ exhibited the highest $\mathrm{H}-\mathrm{OH}$ intensity at $1600 \mathrm{~cm}^{-1}$. This result was agreed with the energy-dispersive X-ray spectroscopy (EDX) data. The band formed at $3460 \mathrm{~cm}^{-1}$ on the zeolite product attests to the attachment of hydroxyl groups to the zeolitic framework $[4,10,31]$. The peak at $1500 \mathrm{~cm}^{-1}$ indicates the formation of aluminum oxide compound; this result indicates the aluminasilicate framework collapses and affording smaller fragments [16]. The $1636 \mathrm{~cm}^{-1}$ band indicates the presence of adsorbed water on zeolite, typically deformation band. The peak about $1000 \mathrm{~cm}^{-1}$ is probably due to internal tetrahedral zeolite structure vibration of asymmetrical stretch, whereas the peaks at the range of $720-650 \mathrm{~cm}^{-1}$ show the symmetrical stretch vibrations of the internal tetrahedral structure of zeolite [16, 19, 35].

Gaidoumi et al. [3] characterized natural clay and modified clays; the FTIR spectrum indicates the presence of the pyrophyllite phase. The absorption peaks at 3674, 854, and $835 \mathrm{~cm}^{-1}$ are assigned to the $\mathrm{OH}$ stretching and 


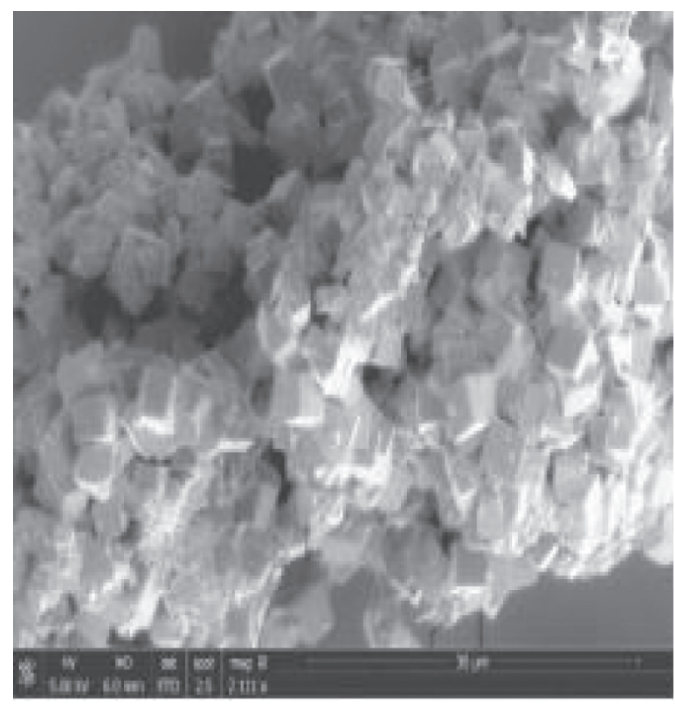

(a)

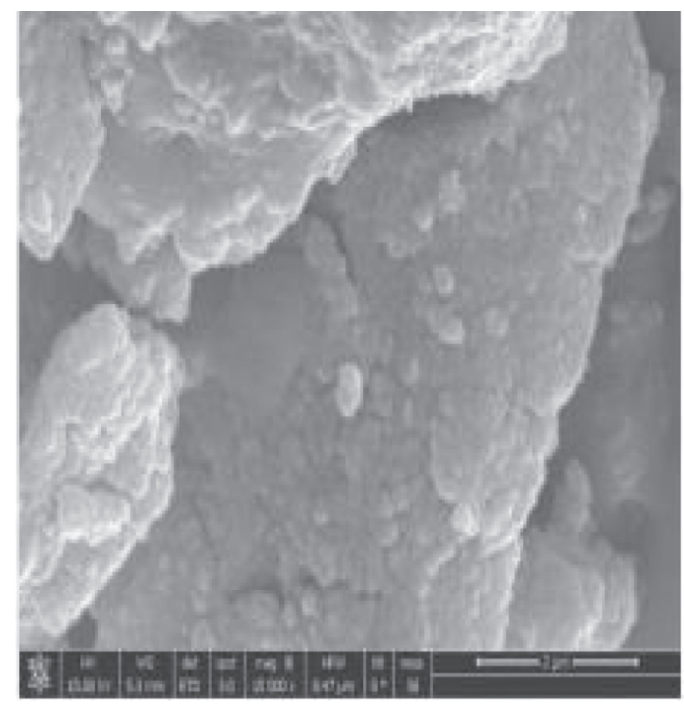

(b)

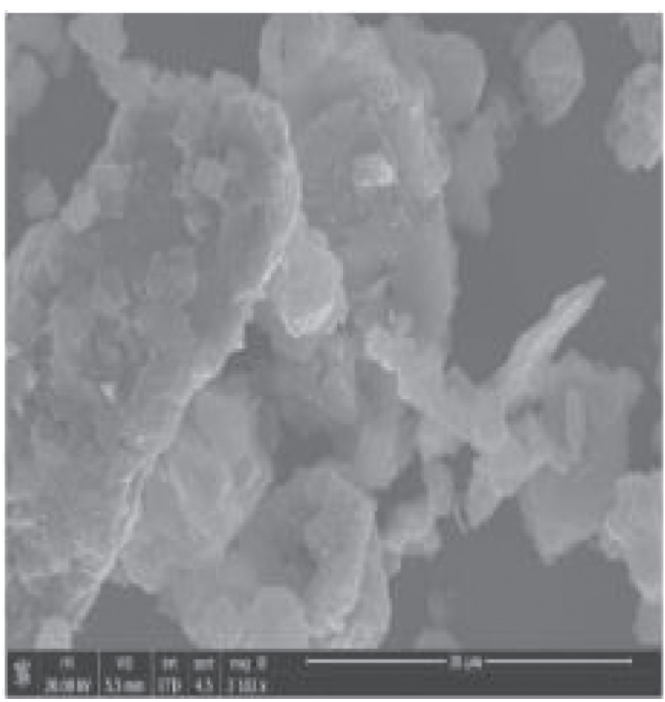

(c)

FiguRE 6: SEM of (a) pure zeolite, (b) $\mathrm{Fe}_{3} \mathrm{O}_{4} \mathrm{NP}$, and (c) zeolite/magnetite nanocomposite $\left(\mathrm{Z}-\mathrm{Fe}_{3} \mathrm{O}_{4} \mathrm{NP}\right)$ reproduced from Nyankson et al. $[12]$.

vibration of $\mathrm{Al}-\mathrm{OH}[3,16]$. The peak at $3446 \mathrm{~cm}^{-1}$ may be attributed to $\mathrm{O}-\mathrm{H}$ stretching surface water molecule and the peak at $1639 \mathrm{~cm}^{-1}$ may be due to $\mathrm{O}-\mathrm{H}$ bending of the adsorbed water [16]. The band at $1428 \mathrm{~cm}^{-1}$ indicates the impurity of carbonate, whilst the peak at $980 \mathrm{~cm}^{-1}$ corresponds to the intense nonbridging $\mathrm{Si}-\mathrm{OH}$ stretching vibration [16]. The bands at 797, 779, and $693 \mathrm{~cm}^{-1}$ indicate the presence of quartz $[16,25]$. The band at $518 \mathrm{~cm}^{-1}$ is ascribed to $\mathrm{Si}-\mathrm{O}-\mathrm{Si}$ bending vibration, while the bending of $\mathrm{Si}-\mathrm{O}$ groups appears at $440 \mathrm{~cm}^{-1}[13,27]$. The spectrum of $\mathrm{PZ}$ indicates the appearance of characteristic vibrational bands of the hydroxyl sodalite phase [16]. The peaks between 3000 and $4000 \mathrm{~cm}^{-1}$ are attributed to $\mathrm{OH}$ related to structural water molecules in the case of synthetic HS $[1,16]$. This was confirmed by the peak at $3626 \mathrm{~cm}^{-1}$ by the XRD study which indicates the presence of the hydroxy sodalite (HS) phase with four water molecules. The bands less than
$1200 \mathrm{~cm}^{-1}$ are attributed to the symmetric and antisymmetric vibrations of $\mathrm{T}-\mathrm{O}-\mathrm{T}(\mathrm{T}=\mathrm{Al}, \mathrm{Si})$. The broad band at $983 \mathrm{~cm}^{-1}$ indicates the asymmetric stretching vibration of T-O-T, while broad bands which appeared at around 731 and $663 \mathrm{~cm}^{-1}$ indicate the symmetric stretching of T-O-T. The absorption bands around 461 and $433 \mathrm{~cm}^{-1}$ indicate bending vibration of O-T-O (Figure 9).

In [18], FT-IR spectra of the natural zeolite showed the band associated with symmetric and asymmetric stretching vibrations of the hydroxyl functional group at $3614 \mathrm{~cm}^{-1}$ and at $1645 \mathrm{~cm}^{-1}$ the vibration of the bond $\mathrm{Si}-\mathrm{O}$, respectively (Figure 10). The band at $1087 \mathrm{~cm}^{-1}$ confirms the vibrations of Al-O bonds, [18, 22]. The authors concluded that the presence of allotropic phase of $\mathrm{SiO}_{2}$ at $797 \mathrm{~cm}^{-1}$ and the $\mathrm{Si}-\mathrm{O}$ and $\mathrm{O}-\mathrm{Al}$ bonds are tectosilicates and is very strong, which suggests that the zeolite has a large surface area [18]. 


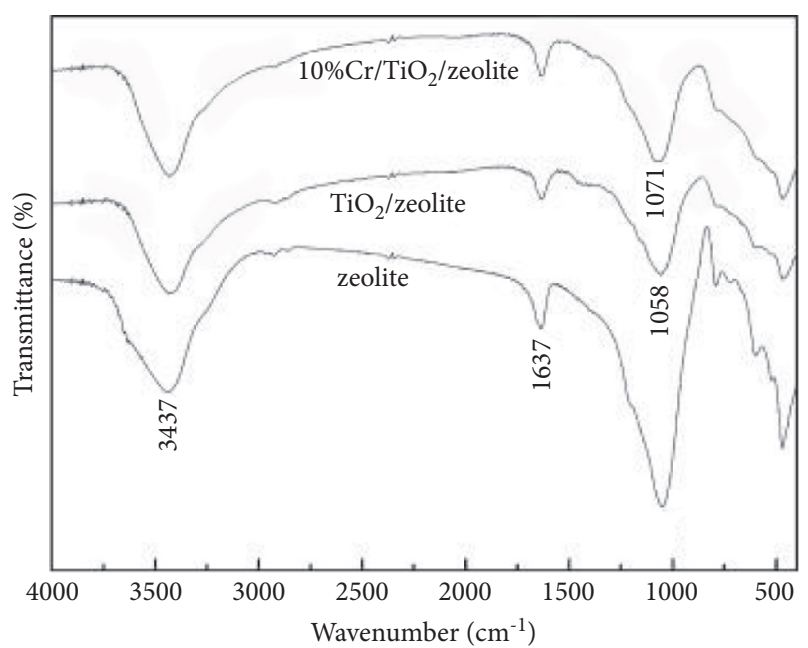

FIGURE 7: FT-IR spectra of zeolite, $\mathrm{TiO}_{2} /$ zeolite, and $10 \% \mathrm{Cr} / \mathrm{TiO}_{2} /$ zeolite adopted from [10].

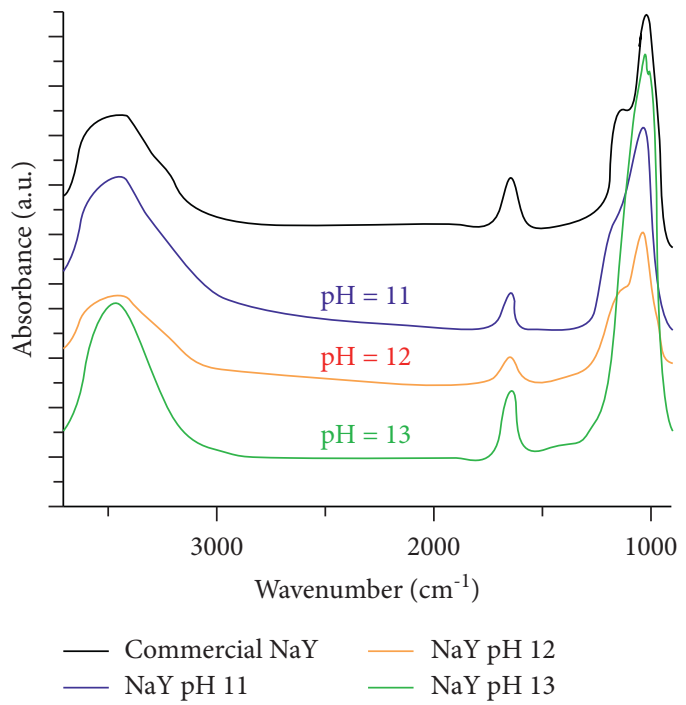

FIGURE 8: FT-IR spectrum of synthesized zeoliteNaY adopted from [16].

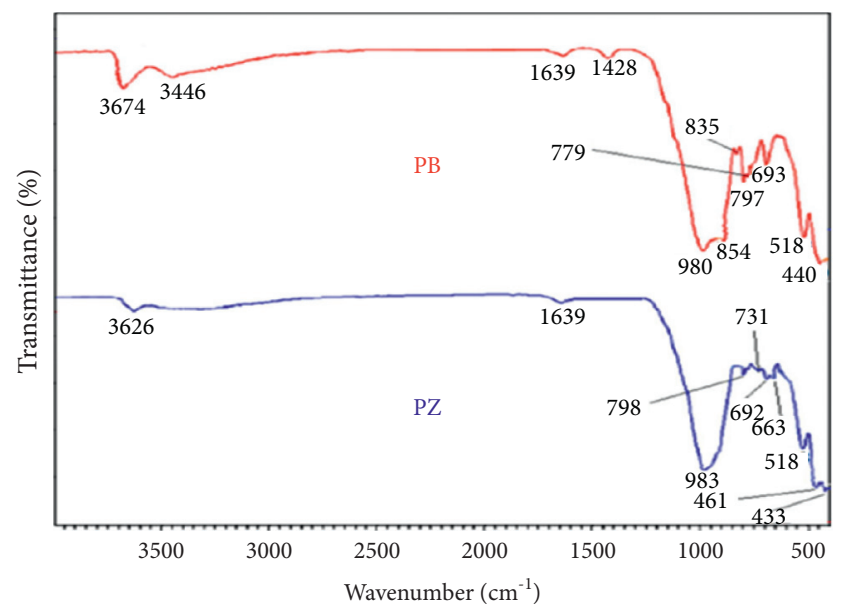

FIGURE 9: FTIR spectra of samples: natural clay (PB) and pyrophyllite (PZ) adopted from [3].

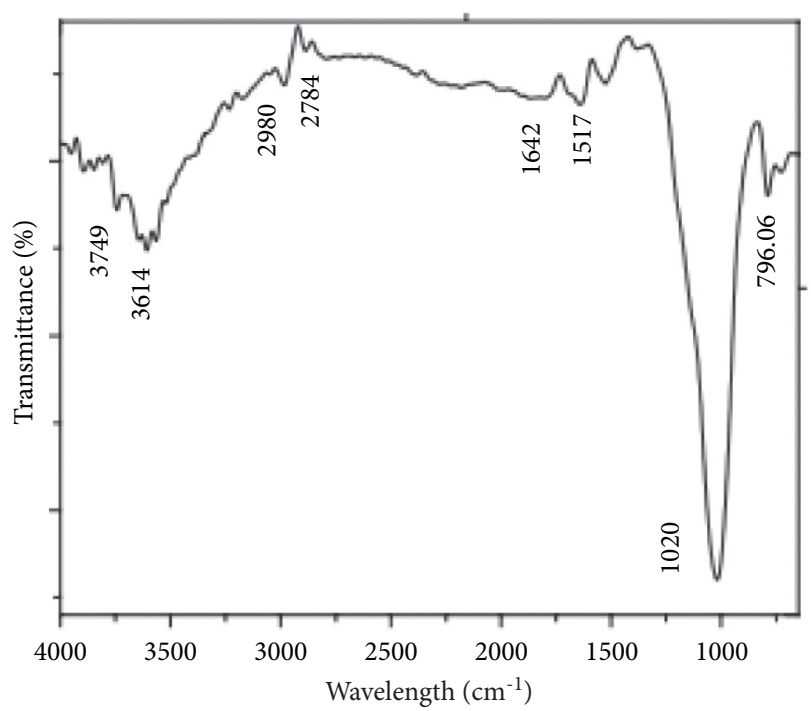

FIGURE 10: FT-IR spectra of the natural zeolite clinoptilolite type adopted from [18].

\section{Application of Zeolites}

The intrinsic properties of zeolites have led vast applications of zeolites such as absorbability, water purification, coagulation activity, membrane separation, and antimicrobial activities; these are associated with their porosity and structural diversity $[18,22]$, their uniform pore size and shape, their mobility of cations, and the hydrophilic and hydrophobic nature of the absorbents and absorbates $[12,46]$. Nowadays, zeolites continue to find various applications in solving environmental, scientifical, and industrial problems [47-49].

4.1. Catalytic Properties of Zeolites. The catalytic activities of zeolites are due to the presence of their active sites (known as bronsted acid) on $\mathrm{OH}$ bridging framework between silicon and aluminum channel $[50,51]$. Substitution of Si atoms in the zeolite framework by trivalent elements creates a negative charge on the lattice that needs to be balanced by a positively charged counterion [43]. When the charge balancing is provided by a proton, a Brønsted acid site is formed. The sites are referred to as bridging hydroxyl which is formed at each oxygen bridge site near the clustering of the $\mathrm{Si}-\mathrm{O}-\mathrm{Al}$ where the cation that neutralizes the negative charge is represented by protons (Scheme 1). The $\mathrm{Si}-\mathrm{OH}-\mathrm{Al}$ sites/ hydroxyl groups are a proton donor $[52,53]$.

Ethyl acetate was synthesized from acetic acid and ethanol through esterification process using zeolite (zeolite A) as the heterogeneous catalyst [49-51]. The zeolite served as a surfactant and is used to shift the equilibrium reaction towards the product by removal of unwanted molecule during the reaction (Scheme 2). The adsorbed acetic acid on the zeolite catalyst forms a chemical linkage with the ethanol, followed by intramolecular dehydration to generate water and ethyl acetate $[49,50,52]$ (Scheme 2). However, the authors did not mention the cause of poor catalyst utilization and decreased catalytic rate such as small pore sizes and long 


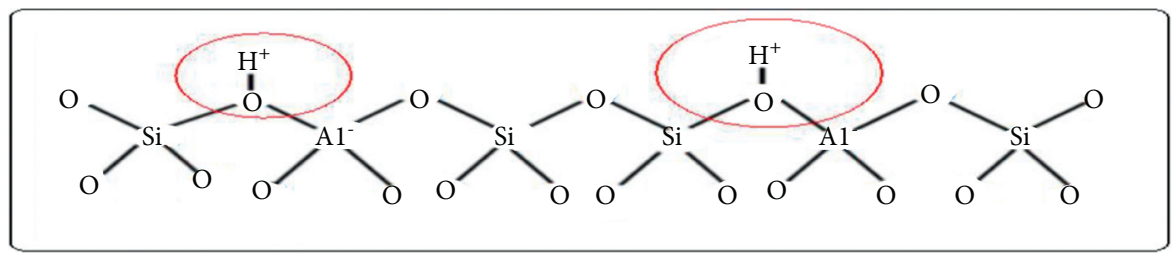

Scheme 1: Brønsted acid sites in zeolites framework [45].

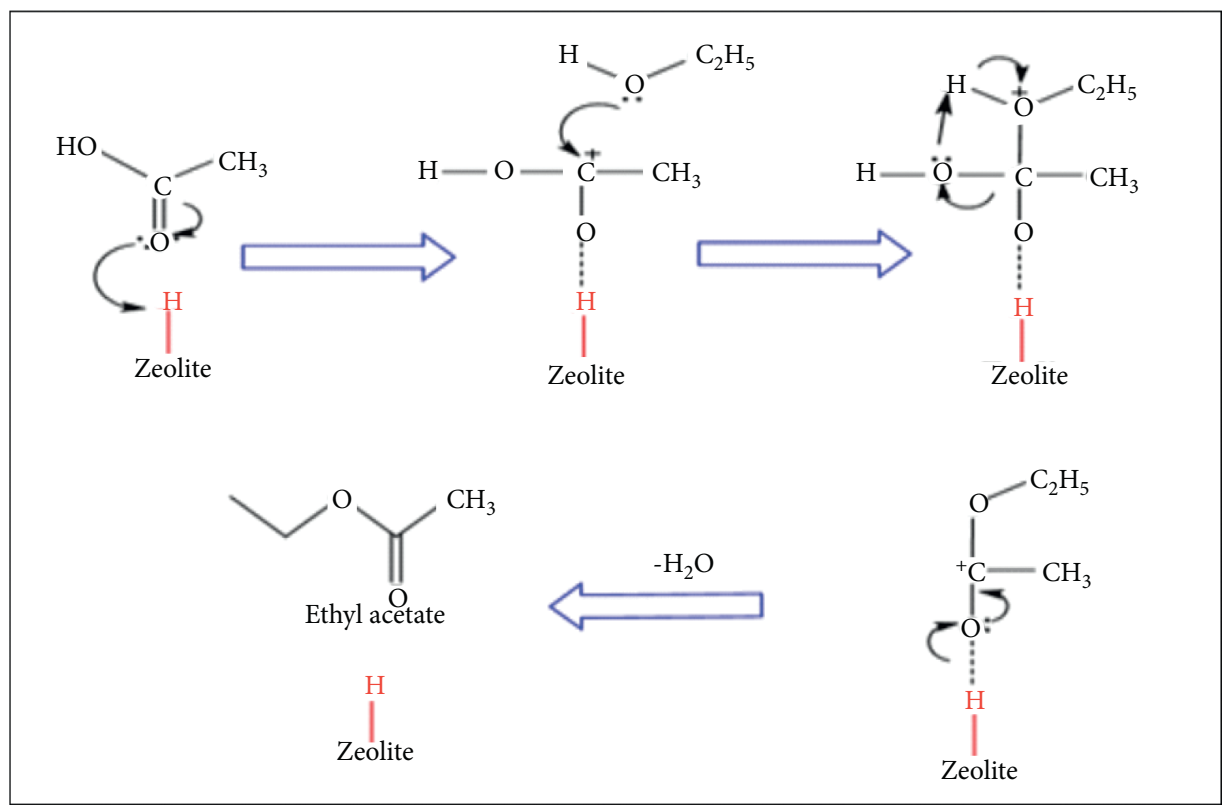

Scheme 2: Vapor-phase acetic acid esterification with ethanol [54].

diffusion path lengths which reduce transport efficiency of catalytic process, enhancing the accessibility of bulky molecules to the active sites located in the zeolite channels and reducing the impact of diffusional limitations while maintaining high selectivity and catalytic activity too important.

Fattahi [54] reviewed the catalysts' role of zeolites in the production of biodiesel through transesterification and esterification reactions, as shown Scheme 3.

Li et al. [49] reviewed the catalytic activity of zeolites on the conversion of microbial produced lactic acid into biodegradable and renewable poly-lactic acid which is lactide (Scheme 4) [51]. The authors concluded that the traditional lactide synthesis method from lactic acid is time and energy consuming, involving condensation and transesterification process at high temperature which leads side products $[24,51]$. Besides, the authors did not consider the effects of aggregation and sinter of impurity into zeolite active site; this causes loss of catalytic performance in practical reaction coordination.

Corma et al. [55] reviewed that the catalyst activity as activated and deactivated during the catalytic process is strongly dependent on the reaction conditions, and numerous factors include the temperature, reactants, pressure, support, metal loading, and particle size. The authors summarized that metal atom may migrate from one porous zeolite site to another across the channel, pore, or cavity in the porous carrier material, as shown in Figure 11. (A) The atomicity of the metal species may change from isolated metal atoms to metal clusters with a few atoms to nanoparticles with tens or hundreds of atoms during reaction conditions and the physicochemical properties of the catalyst. (B) Potential structural transformation of supported single-atom alloy nanoparticles under reaction conditions or change of the atmosphere; segregation may occur with single-atom alloy nanoparticles. (C) By contrast, bimetallic nanoparticles with chemical segregation may be transformed into single-atom alloy nanoparticles under the proper reaction conditions.

In current situation, encapsulation of transition metal and their complexes into zeolites is a promising process to enhance the catalytic activity in different reaction routes. Pan et al. [14] reviewed on microporous and hierarchical zeolites to improve the catalytic activity, especially to enhance catalyst lifetime for potential industrial applications. Risheng et al. [56] reviewed the microporous and mesoporous zeolites in hierarchical zeolites that are favorable to overcome the mass-transfer issues associated with microporous zeolites. Thus, the diffusion and steric limitations of bulky molecules and the pore-blocking effect of deposited coke species can be reduced, affording high utilization 


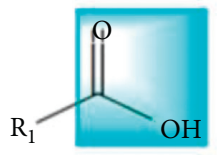

Free Fatty Acid

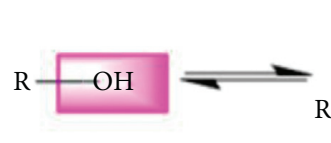

Alcohol

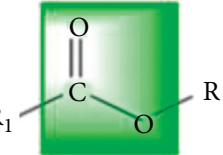

Alkyl ester
$\mathrm{H}_{2} \mathrm{O}$

Water

(a)

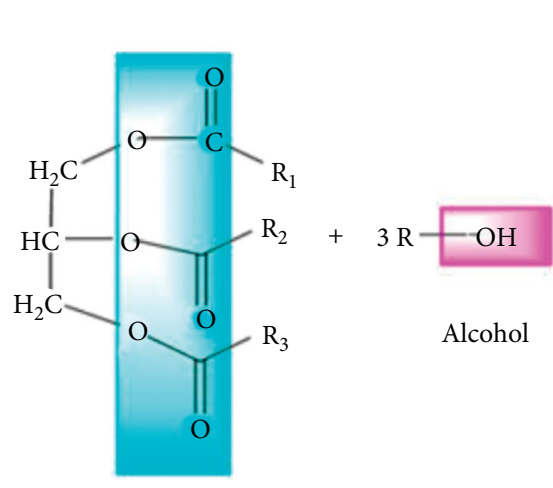

Trigllyceride (TAG)

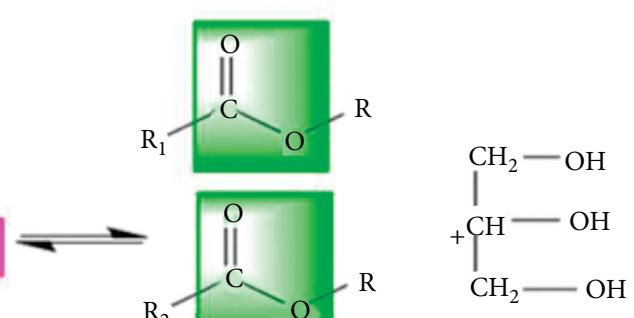

Glycerol

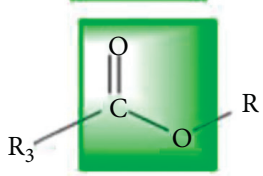

Alkyl ester

(b)

Scheme 3: Production of biodiesel (alkyl ester) via (a) esterification and (b) transesterification reaction [54].

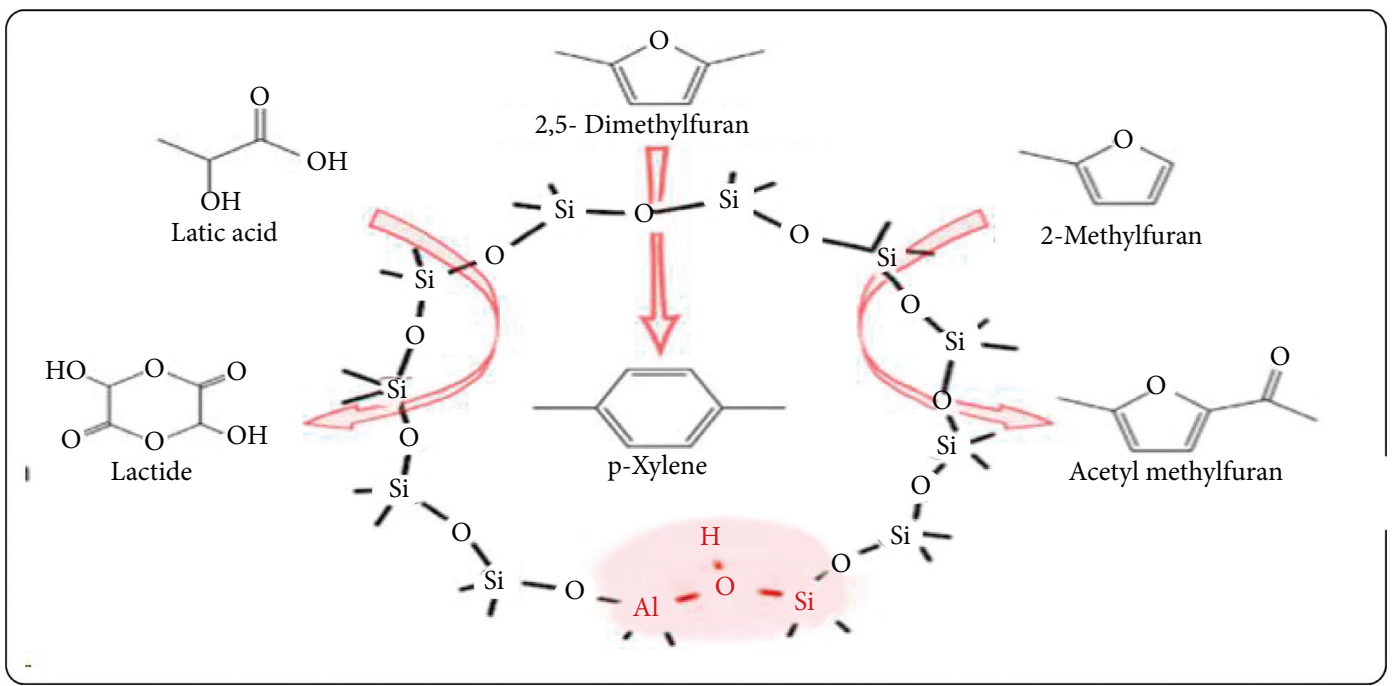

Scheme 4: Reactions over a Brønsted acid site adopted from the work of Li et al. [49].

efficiency, prolonged catalytic lifetime, and improved catalytic performance of zeolite catalysts. These synthetic strategies afford hierarchical zeolite characteristics (e.g., distribution, dimensionality, connectivity, and even ordering of secondary pores) to be tuned to enhance the diffusivity of bulky molecules and the accessibility of the substrates to the active sites of the catalysts. Besides, the authors highlighted that hierarchical zeolites offer the potential to reduce steric limitations for converting bulky molecules, increase the rate of intracrystalline diffusion, inhibit deactivation due to coking, maximize catalyst utilization, and modulate [54].
4.2. Adsorption Properties of Zeolites. The adhering mechanism of zeolite is affected via adsorption equilibrium, rate of adsorption selectivity, adsorbate shape, ion exchanging processes (adsorption), and reactivity of the adsorbate and adsorbents [57]. Nyankson et al. [12] studied the feasibility of synthesized $\mathrm{Zn}$ exchangeable zeolite A to adsorb methylene blue (MB) from solution through adsorption kinetics $[44,57,58]$. The authors concluded that the adsorption of $\mathrm{MB}$ on to $\mathrm{Zn}$-exchanged zeolite $\mathrm{A}$ is affected by contact time; the adsorption equilibrium reached within $180 \mathrm{~min}$ (Figure 12). The synthesized Zn-exchanged zeolite shows strong 


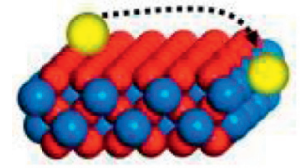

Migration on surface

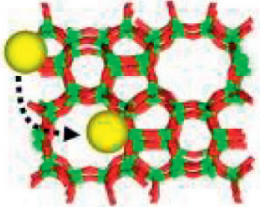

Migration in porous material

(a)

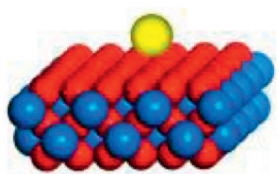

Supported isolated atoms

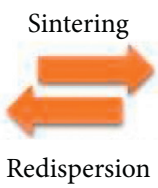

Redispersion

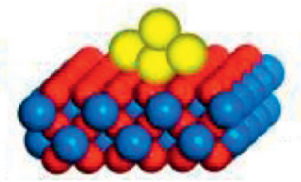

Supported metal cluster

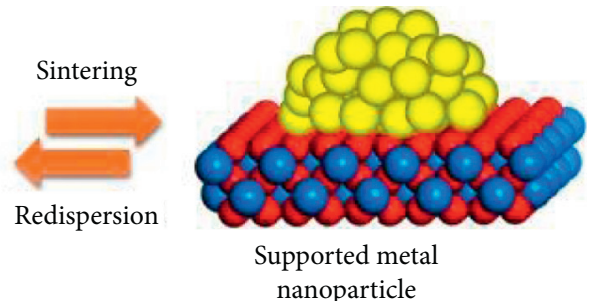

(b)
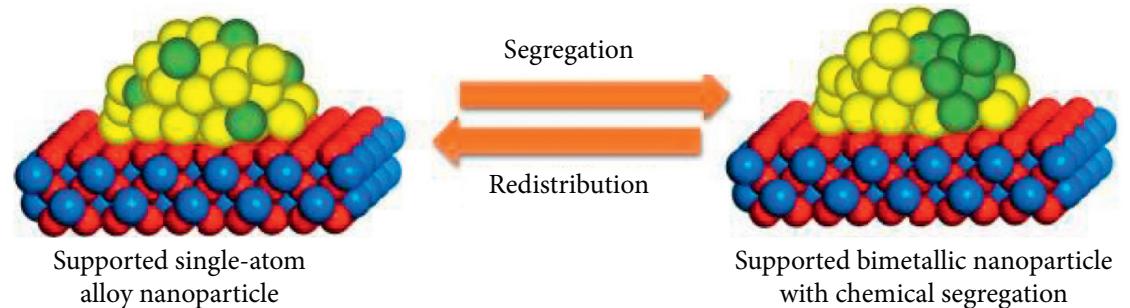

(c)

Figure 11: The structures of heterogeneous metal catalysts adopted from [55]. (a) Change of coordination environment. (b) Change of size. (c) Change of spatial distribution of the chemical compositions.

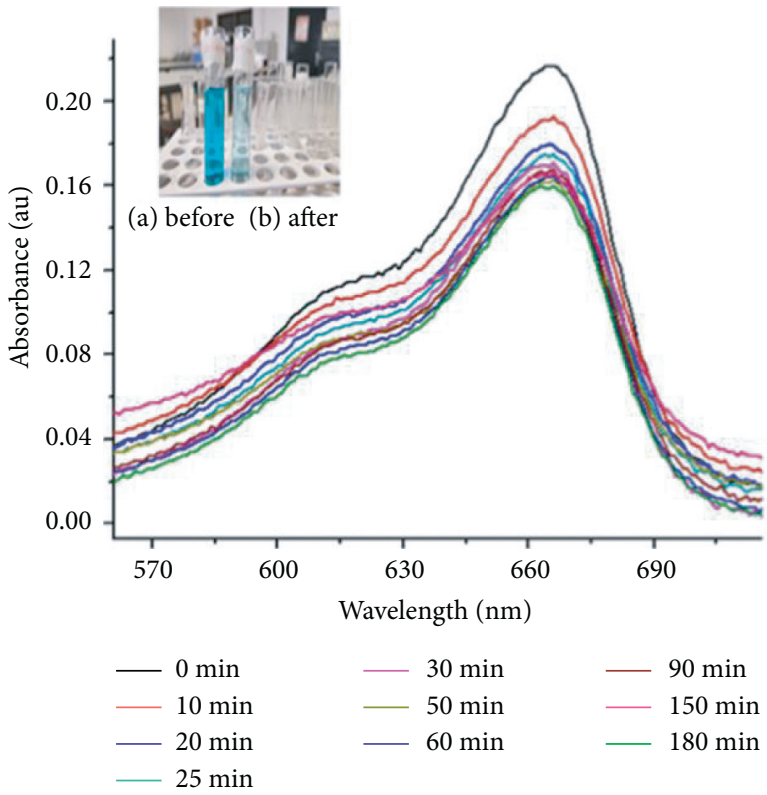

Figure 12: Absorbance intensity curve at various time intervals adopted from the work of Nyankson et al. [12].

adsorption for methylene blue dye at optimum contact time, as shown in $[57,59]$. However, the authors did not recognize the effects of competing agents during adsorption of $\mathrm{MB}$.

Chojnacki et al. [22] studied the sorption mechanism (adsorption and ion exchange) of natural zeolite
(Clinoptilolite) for removal of mercury from industrial effluent [22]. The authors' inferred zeolite capable for removal of mercury ion from water by trapping the cation with negative end of sorbent surface (zeolite) [49, 51]. Nevertheless, the ion exchange and adsorption process of mercury ion via zeolite is highly $\mathrm{pH}$ dependent $[58,59]$. Besides, the authors did not mention the presence of the hindering agent (more active metal ions) during the sorption process. Ghadamnan et al. [46] studied the effect of competitive ions adsorption in the nano-LTA zeolite using $\mathrm{Ca}^{2+}$ and $\mathrm{Mg}^{2+}$ ions in the binary system [46]. As can be seen in Figure 13, the adsorption capacity of ions increased with initial concentration of $\mathrm{Ca}^{2+}$ and $\mathrm{Mg}^{2+}$ ions as well as adsorption time $[46,57]$. The authors concluded the adsorption rates of $\mathrm{Ca}^{2+}$ ion are faster than $\mathrm{Mg}^{2+}$ ions to exchange at $15 \mathrm{~min}$ and rapidly reached the equilibrium point. Furthermore, the exchangeability of $\mathrm{Ca}^{2+}$ is higher than $\mathrm{Mg}^{2+}$ on nano-LTA zeolite; this is because $\mathrm{Mg}^{2+}$ exists in the form of hydrate in the solution, which makes it hard to exchange with $\mathrm{Na}^{+}$in zeolite $[28,58]$. According to the competitive exchange data, nano-LTA zeolite possesses a large amount of $\mathrm{Ca}^{2+}$ ions that competes with $\mathrm{Mg}^{2+}$ in the adsorption process $[29,60]$.

Many researchers, such asTran et al. [57], modified zeolite adsorption using dual-electronic adsorbent for removal of cationic, oxyanionic, and organic compounds. Na$\mathrm{H}$-zeolite (composite zeolite) can be regarded an amphiphilic and dual-electronic adsorbent, which is used to remove toxic pollutants from wastewater $[46,57]$. Zeolites 


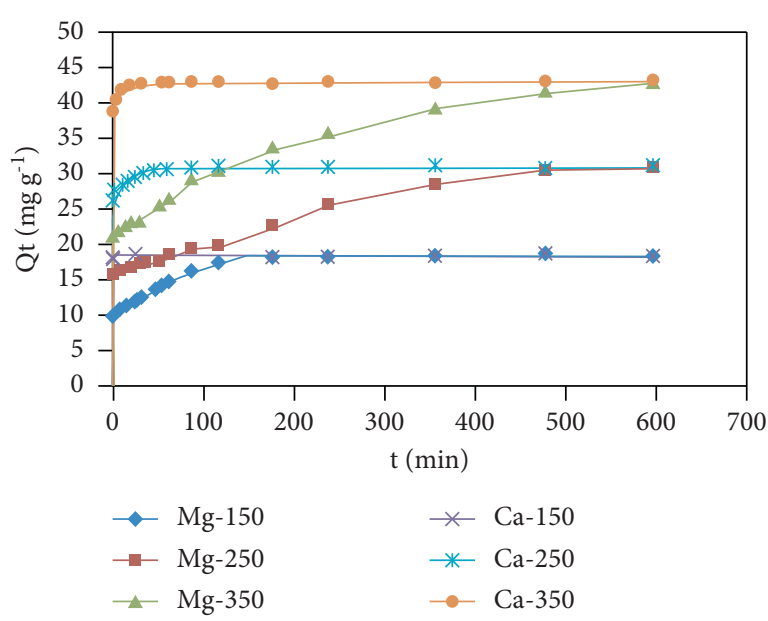

Figure 13: The $\mathrm{Ca}^{2+}$ and $\mathrm{Mg}^{2+}$ competitive exchange data with different initial concentration adopted from the work of Ghadamnan et al. [46].

with high ion exchange capability have high level of selective during adsorption. This was achieved using high silica zeolite absorber which is specific for hydrophilic and hydrophobic adsorbates [12, 22, 57].

4.3. Ion Exchange Properties of Zeolites. The primary building units (PBU) of zeolites are the $\mathrm{SiO}_{4}$ and $\mathrm{AlO}_{4}$ tetrahedra structure [2]. They connect via oxygen ions into secondary building units (SBU), which are then linked into a $3 \mathrm{D}$ crystalline structure of zeolite $[2,18]$. Substitution of Si by Al results in the negative charge of the zeolite framework, which is compensated by alkaline and Earth alkaline metal cations $[4,5]$. The created net negative charge which exists on zeolite ends is balanced by active metal ions such as $\mathrm{Na}^{+}$, $\mathrm{K}^{+}, \mathrm{Ca}^{2+}$, and $\mathrm{Mg}^{2+}$. These positive ions are rather loosely held and can be readily exchangeable between zeolite $(Z)$ in a contact solution, as shown in the reaction below [61]. The ion exchange properties of zeolites are widely used in detergents and treatment of waste and hard water $[49,50]$. The replacement of insoluble $\mathrm{Cr}$ and As ions by active metals is used for removal of Cr (VI) and As (V) from solution [57].

Tsitsishvili et al. [37] carried out a study on ion exchange properties of Georgian zeolite of analcime, phillipsite, and scolecite $[13,27,37]$. The exchange capacity of analcimes is $\mathrm{Na}^{+}>\mathrm{K}^{+}>\mathrm{Ag}^{+}>\mathrm{NH}_{4}^{+}>\mathrm{Ca}^{+2}>\mathrm{Sr}^{+2}>\mathrm{Li}^{+}$; however, ion exchange isotherms prove the high selectivity of phillipsite is $\mathrm{K}^{+}>\mathrm{NH}_{4}^{+}>>\mathrm{Ca}^{+2}>\mathrm{Mg}^{+2}$. The authors concluded as the Georgian natural zeolite: analcime, phillipsite, and scolecite are used as ion exchangers and can substitute the synthetic materials in local industrial and environmental applications [37, 57].

4.4. Water Purification. Zeolites are used in purification of wastewater from various sources including natural, industrial, agricultural, and municipal waste that contain metal ions $\mathrm{Sb}, \mathrm{Cr}, \mathrm{Cu}, \mathrm{Pb}, \mathrm{Zn}, \mathrm{Co}$, and $\mathrm{Ni}$, together with waste liquids which are generated by metal finishing [58]. The dissolved cations are removed from water by being exchanged with the cations on a zeolite's extra-framework exchange active sites [29, 58]. Tsitsishvili et al. [37] and Wang and Pen [35] carried out a study on many natural zeolites (clinoptilotite, mordenite, philtipsite, and chabasite) for removing toxic metals from industrial waters $\left(\mathrm{Cu}^{2+,} \mathrm{Ag}^{+}\right.$, $\mathrm{Zn}^{2+}, \mathrm{Cd}^{2+}, \mathrm{Hg}^{2+}, \mathrm{Pb}^{2+}, \mathrm{Cr}^{3+}, \mathrm{Mo}^{2+}, \mathrm{Mn}^{2+}, \mathrm{Co}^{2+}$, and $\mathrm{Ni}^{2+}$ ); these zeolites are highly selective for $\mathrm{NH}^{4+}$ ion even in the presence of competing cations $[29,54]$. The authors revealed that toxic metal ions are removed from water and replaced with biologically acceptable cations such as $\mathrm{Na}^{+}, \mathrm{K}^{+}, \mathrm{Mg}^{2+}$, $\mathrm{Ca}^{2+}$, or $\mathrm{H}^{+}$from the zeolite exchange sites [60].

Pitcher et al. [52] studied the removal of heavy metals from motorway storm water using synthetic zeolites [50, 52]. Zeolite is effective in removing heavy metals, but is affected by $\mathrm{pH}$ of solution [58]. At very low $\mathrm{pH}$ values, alumino groups in zeolite are protonated, whereas at high $\mathrm{pH}$, they are deprotonated by hydroxyl ions (Scheme 5). The heavy metal ions react with protonated or neutral alumino groups, as shown in Scheme 5.

Hui et al. [50] showed comparative study on zeolites that is prepared from coal fly and commercial zeolite $4 \mathrm{~A}$ for removal of heavy metals from aqueous solution [50]. They concluded zeolites that were prepared from coal fly are used as an alternative adsorbent of heavy metal ion from wastewater; the sorption rate and process of metal ions are high at $\mathrm{pH}$ value $4[3,50]$. Figueiredo and Quintela [61] studied on the adsorption of heavy metal ions and oxyanions via metal modified zeolite (MMZ). This adsorption process is either a simple ion exchange or through formation of metal oxide on zeolites [54]. Counter ions mainly groups IA and IIA metals' presence in zeolites which are easily soluble and replace via insoluble Cr (VI), As (V), Ag (I), Al (III), Ba (II), Fe (III), Pb (II), and other less soluble metal ions $[46,54,60]$. The authors concluded MMZ used for removal of As (V), Ag (I), Al (III), $\mathrm{Ba}$ (II), Fe (III), and $\mathrm{Pb}$ (II) by trapping on the internal and external sites of the modified zeolites (Figure 14).

Jiahui et al. [62] modified zeolite in terms of physical modification, chemical modification, and composite modification to increase the adsorption potential of zeolite for various pollutants from wastewater. The authors concluded physical modification was only related to ammonium removal whilst chemical modification and composite modification were widely for eliminating varied kinds of pollutants. Modified zeolite as a substrate can greatly improve the removal rate of pollutants and alleviate the clogging conditions of pollutants. However, the authors did not support the physical and chemical modification through adsorption models.

Nowadays, zeolites have been playing a great role in wastewater treatment, in industrial production, in hard water treatment, and in catalytic process due to their internal and external porous [46]. Zeolites have a potential for adsorption of impurities, removal of metal ions, and removal of pollutants from wastewater mainly ammonium, anions, phosphorus, and heavy metals, as shown in Figure 15.

4.5. Agricultural Application of Zeolites. Ippolito et al. [63] studied application of zeolites in soil neutrality, maintaining soil moisture, and preventing losses of $\mathrm{NH}_{4}{ }^{+}$ions against 


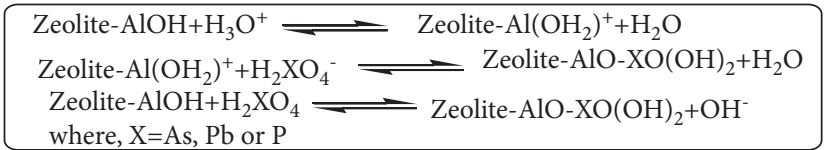

Scheme 5: Heavy metal removal mechanism via zeolites [52].

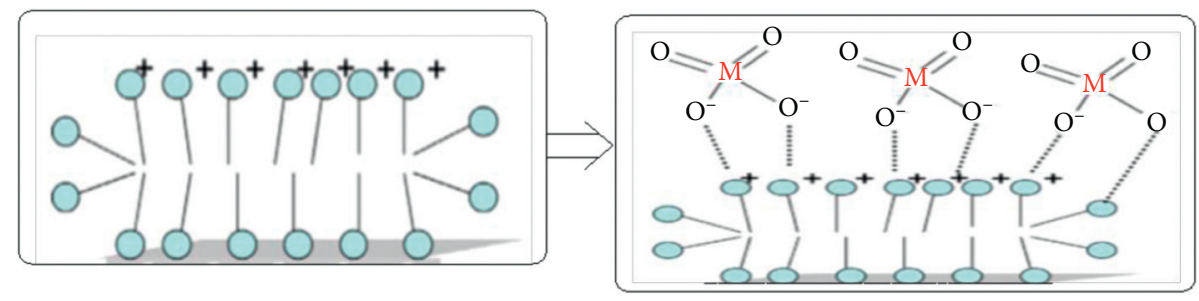

FIGURE 14: Adsorption of a metal oxyanion on a SMZ adopted from [61].

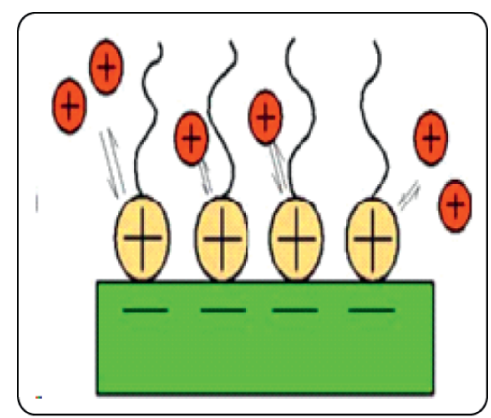

(a)

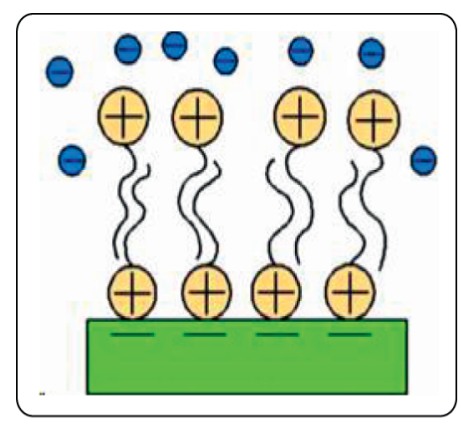

(b)

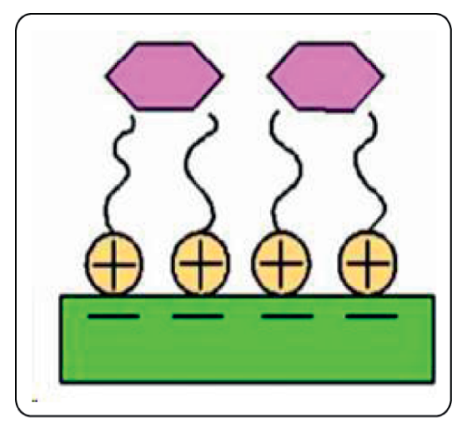

(c)

FIGURE 15: Mechanism of cation (a), anion (b), and organic (c) removal by cationic surfactants on the zeolite surface [29].

microbial nitrification; mixing zeolite into soil reduced the rate of nitrification likely because of $\mathrm{NH}_{4}{ }^{+}$adsorption in the zeolite mineral lattice. Thus, mixing zeolite into soil may reduce the leaching of inorganic $\mathrm{N}$ and improve the soil water status, although initial leaching of zeolite-borne $\mathrm{Na}$ may be necessary before growing crops. The authors compared the growth of corn using urea fertilizer and zeolite mixed urea fertilizer; results showed that zeolite mixed with urea fertilizer increases corn weight and seed yield than unmixed urea fertilizer. This is probably due to high selectivity of zeolites for $\mathrm{NH}_{4}{ }^{+}$and $\mathrm{K}^{+}$.

Reháková et al. [64] carried out the study on natural zeolite of the clinoptilolite in agrochemicals' process such as fertilizers; natural zeolites are effective in improving soil properties and treating contaminated soil. The authors concluded that feed zeolites in soil improve the efficiency of nutrient use by increasing the availability of $\mathrm{P}$ from phosphate rock, the utilization of $\mathrm{N}_{-} \mathrm{NH}_{4}{ }^{+}$and $\mathrm{N}_{-} \mathrm{NO}_{3}{ }^{-}$, and reduced losses by leaching of exchangeable cations, especially K. Besides, zeolites enhance the seedling growth and crop products. However, the authors did not mention the effects of zeolite on soil acidity.

Mumpton and Frederick [65] studied the natural zeolite (clinoptilolite) in soil amendments for sandy, clay-poor soils. Clinoptilolite has highly selectivity for $\mathrm{NH}_{4}{ }^{+}$and $\mathrm{K}^{+}$and is slow-release chemical fertilizer. The author deduced clinoptilolite-rich tuff as a soil conditioner which provides significant increment in the yields of wheat (13-15\%), eggplant (19-55\%), apples (13-38\%), and carrots (63\%). The author concluded that nutrient-treated zeoponic substrate used for growing crops and the rooting of cuttings in greenhouses produced greater root systems and larger yields of strawberries, tomatoes, and peppers, without further fertilization.

Currently, zeolites are used in the agricultural sector to ensure food security owing to their enrichment with $\mathrm{N}, \mathrm{P}$, and $\mathrm{K}$ and adequate slow release of those nutrients to plants. Zeolite is used as soil conditioner or amendment by improving soil nutrient retention, water infiltration, reduced water run-off and reduced surface water run-off, and nutrient leaching. Benefits from zeolite application could translate to increased yield, more efficient use of nutrient inputs, and reduction in environmental pollution of nitrogen $(\mathrm{N})$ and phosphorus $(\mathrm{P})$ in water bodies, as well as reduction in greenhouse gas emissions. However, the use of zeolites in crop production increases soil $\mathrm{pH}$ to undesirable levels.

\section{Conclusion and Perspective}

In conclusion, the synthesis methods of zeolites depend on many factors: composition of precursors, $\mathrm{pH}$ of the reaction, temperature, pretreatment of precursors, seeding time, 
reaction time, and templates used. Microwave synthesis methods are now widely used in many zeolite syntheses due to their fast and energy efficient techniques to avoid competitive reactions in many known processes. Sol-gel synthesis process also advanced the method for zeolite synthesis due to easily encapsulation of elements (metals or metal oxides) into cavities. Nevertheless, employing a two-step crystallization process in hierarchical porous zeolite synthesis is promising; combining hydrothermal crystallization with microwave heating technique is one more synthesis method giving smaller and more uniform particles in a shorter time. Combinations of two or more synthesis methods are required such as solid-state or quasi-solid-state synthesis with the aid of a microwave, and it can be considered because of the high crystallization rate and high product yield. However, this may lead to formation of aggregation and diffusion limitations; thus, using hierarchical approach is too important to enhance the diffusion and the catalytic properties of zeolite materials. Beyond this, using computational approach such as density functional theory (DFT), Gaussian, and AOMix have significant contributions to elucidate the molecular nature of active sites in zeolite catalysts.

The review also highlighted different characterization methods by organizing related literatures that are carried out in different chronological time sequences. On the basis of characterization results, zeolites show inherent properties such as uniform pore size/shape, acidic properties, thermal stability, mobile cation, and surface properties such as hydrophobicity and hydrophobicity. These lead a number of applications of zeolites such as catalysis, ion exchanger, water purification, adsorption, and agricultural applications [66].

\section{Conflicts of Interest}

The authors declare that they have no conflicts of interest.

\section{References}

[1] E. O. Odebunmi, F. O. Nwosu, A. O. Adeola, and T. G. Abayomi, "Synthesis of zeolite from kaolin clay from ErusuAkoko southwestern Nigeria. G. Olaremu," Journal of Chemical Society of Nigeria, vol. 43, pp. 1-7, 2018.

[2] N. O. Omisanya, C. O. Folayan, S. Y. Aku, and S. S. Adefila, "Synthesis and characterization of zeolite a for adsorption refrigeration application," Advances in Applied Science Research, vol. 6, pp. 3746-3754, 2012.

[3] A. El Gaidoumi, A. C. Benabdallah, B. E. Bali, and A. Kherbeche, "Synthesis and characterization of zeolite HS using natural pyrophyllite as new clay source," Arabian Journal for Science and Engineering, vol. 43, pp. 1-8, 2011.

[4] M. Moshoeshoe, M. S. Nadiye-Tabbiruka, and V. Obuseng, "A Review of the chemistry, structure, Properties and Applications of zeolites." American Journal of Materials Science, vol. 7, pp. 196-221, 2017.

[5] M. N. Orjioke, O. Uchechukwu, C. N. Igwe, and U. Ajah, "Synthesis and characterization of zeolite and its application in adsorption of nickel from aqueous solution." Journal Pharmaceutical and Chemical Biological Science, vol. 4, pp. 592-600, 2016.
[6] H. E. Mgbemere and I. C. Ekpe, "Zeolite synthesis, characterization and application areas: a review." International Research Journal of Environmental science, vol. 10, pp. 45-59, 2017.

[7] H. Ramezani, S. N. Azizi, and G. Cravotto, "Improved removal of methylene blue on modified hierarchical zeolite $\mathrm{Y}$ : achieved by a "destructive-constructive" method," Green Processing and Synthesis, vol. 8, no. 1, pp. 730-741, 2019.

[8] L. Bacakova, M. Vandrovcova, I. Kopova, and I. Jirka, “Applications of zeolites in biotechnology and medicine - a review," Biomaterials Science, vol. 6, no. 5, pp. 974-989, 2018.

[9] V. Petranovskii, F. Chaves-Rivas, M. A. H. Espinoza, A. Pestryakov, and E. Kolobova, "Potential uses of natural zeolites for the development of new materials: short review," vol. 85 , pp. 1-5, 2016.

[10] C. Wang, H. Shi, and Y. Li, "Synthesis and characterization of natural zeolite supported Cr-doped TiO2 photocatalysts," Applied Surface Science, vol. 258, no. 10, pp. 4328-4333, 2012.

[11] C. J Rhodes and J. Christopher, "Properties and applications of zeolites,” Science Progress, vol. 93, pp. 223-284, 2010.

[12] E. Nyankson, J.K. Efavi, A. Yaya, G. Manu, K. Asare, and J. Daafuor, "Synthesis and characterization of zeolite-A and Zn-exchanged zeolite-A based on natural aluminosilicates and their potential applications," Cogent Engineering, vol. 5, pp. 1-23, 2018.

[13] W. Chunfeng, L. Jiansheng, S. Xia, W. Lianjun, and S. Xiuyun, "Evaluation of zeolites synthesized from fly ash as potential adsorbents for wastewater containing heavy metals," Journal of Environmental Sciences, vol. 21, pp. 127-136, 2009.

[14] T. Pan, Z. Wu, C. Alex, and K. Yip, "Advances in the green synthesis of microporous and hierarchical zeolites: a short review," Catalysts, vol. 9, pp. 1-18, 2019.

[15] D. Georgiev and S. Zagora, "Synthetic zeolites - structure, classification, current trends in zeolite synthesis: review," in Proceedingas of the International Science conference, pp. 1-6, Jeju Island, Korea, December 2009.

[16] G. S. A. Melaningtyas, Y. K. Krisnandi, and R. Ekananda, "Synthesis and characterization of $\mathrm{NaY}$ zeolite from Bayat natural zeolite: effect of $\mathrm{pH}$ on synthesis," Materials Science and Engineering, vol. 496, pp. 1-5, 2019.

[17] L. Deng, Q. Xu, and H. Wu, "Synthesis of zeolite-like material by hydrothermal and fusion methods using municipal solid waste fly ash," Procedia Environmental Sciences, vol. 31, pp. 662-667, 2016.

[18] A. Ruíz-Baltazar, R. Esparza, M. Gonzalez, G. Rosas, and R. Pérez, "Preparation and characterization of natural zeolite modified with iron nanoparticles," Journal of Nanomaterials, vol. 2015, pp. 1-8, 2015.

[19] S. Manafia and S. Joughehdoust, "Production of zeolite using different methods," in proceedings of the Iran International Zeolite Conference, pp. 1-7, Tehran, Iron, May 2008.

[20] Jujarama, K. Wijaya, M. Shidiq, M. Fahrurrozi, and Suheryanto, "Synthesis of biogasoline from used palm cooking oil through catalytic hydrocracking by using $\mathrm{Cr}$-activated natural zeolite as catalyst," Asian Journal of Chemistry, vol. 26, no. 16, pp. 5033-5038, 2014.

[21] W. J. Roth, P. Nachtigall, R. E. Morris, and J. Čejka, "Twodimensional zeolites: current status and perspectives." Chemical Reviews, vol. 114, no. 9, pp. 4807-4837, 2014.

[22] A. Chojnaki, K. Chojnacka, J. Hoffmann, and H. Gorecki, "Application of natural zeolite for mercury removal: from laboratory tests to industrial scale," Minerals Engineering, vol. 17, pp. 933-937, 2004. 
[23] G. Yao, J. Lei, X. Zhang, Z. Sun, and S. Zheng, "One- hydrothermal synthesis of zeolite X powder from natural lowgrade diatomit,” Materials, vol. 11, pp. 1-14, 2018.

[24] Z. Liu, C. Shi, D. Wu, S. He, and B. Ren, "A simple Method of Preparation of high silica zeolite $\mathrm{Y}$ and its Performance in the catalytic Cracking of cumene," Journal of Nanotechnology, vol. 2016, pp. 1-6, 2016.

[25] J. Luo, H. Zhang, and J. Yang, "Hydrothermal synthesis of sodalite on alkali-activated coal fly ash for removal of lead ions," Procedia Environmental Sciences, vol. 31, pp. 605-614, 2016.

[26] K.D. Pandiangan, W. Simanjuntak, H. Sutopo, I. Ilim, and H. anif Amrulloh, "Physical characteristics and utilization of ZSM-5 prepared from rice husk silica and aluminum hydroxide as catalyst for transesterification of Ricinus communis oil," Materials Research Express, vol. 8, pp. 1-8, 2021.

[27] W. Chester and E. G. Derouane, Zeolite Characterization and Catalysis, Springer, New York, NY, USA, 2001.

[28] E. R. Cooper, C. D. Andrews, P. S. Wheatley, P. B. Webb, P. Wormald, and R. E. Morris, "Ionic liquids and eutectic mixtures as solvent and template in synthesis of zeolite analogues," Nature, vol. 430, no. 7003, pp. 1012-1016, 2004.

[29] J. Shi, Z. Yang, H. Dai, X. Lu, and L. Peng, "Preparation and application of modified zeolites as adsorbents in wastewater treatment," Water Science and Technology, pp. 1-15, 2018.

[30] E. R. Pamham and R. E. Morris, "The ionothermal synthesis of cobalt aluminophosphate zeolite frameworks," Journal of the American Chemical Society, vol. 128, pp. 2204-2205, 2006.

[31] Y. Xiao, N. Sheng, Y. Chu, and Y. Wang, Q. Wu, X. Liu, F. Deng, X. Meng, and Z. Feng, Mechanism on solvent-free crystallization of NaA zeolite," Microporous and Mesoporous Materials, vol. 237, pp. 201-209, 2017.

[32] L. R. G. d. Araújo, C. L. Cavalcante, K. M. Farias et al., "Synthesis of cubic Y zeolite using a pulsed microwave heating system," Materials Research, vol. 2, no. 2, pp. 105-109, 1999.

[33] M. Sathupunya, E. Gulari, and S. Wongkasemjit, "Microwave preparation of Li-zeolite directly from alumatrane and silatrane," Materials Chemistry and Physics, vol. 83, no. 1, pp. 89-95, 2004.

[34] S. K. P. Veerapandian, N. De Geyter, J.-M. Giraudon, J.-F. Lamonier, and R. Morent, "The use of zeolites for VOCs abatement by combining non-thermal plasma, adsorption, and/or catalysis: a review," Catalysts, vol. 9, no. 1, p. 98, 2019.

[35] S. Wang and Y. Peng, "Natural zeolites as effective adsorbents in water and wastewater treatment," Chemical Engineering Journal, vol. 156, no. 1, pp. 11-24, 2010.

[36] Sudiyarmanto, "Preparation and characterization of Ni based on natural zeolite catalyst for citronellol conversion to 3, 7Dimethyl-1-Octanol." in Proceedings of the 3rd International Symposium on Applied Chemistry, Jakarta, Indonesia, October 2017.

[37] V. Tsitsishvili, N. Dolaberidze, S. Urotadze, M. Alelishvili, N. Mirdzveli, and M. Nijaradze, "Ion exchange properties of Georgian natural zeolites," Chemistry Journal of Moldova, vol. 12, no. 1, pp. 95-101, 2017.

[38] X. Yongquan, C. Lianguo, L. Shao, and C. Jianfeng, "Preparation and characterization of NaY zeolite," Pet.Sci, vol. 8, pp. 106-109, 2012.

[39] C. hongwei, L. Shuang, and Y. Yushan, "Synthesis of templatefree zeolite nanocrystals by Reverse," Chemistry of Materials, vol. 17, pp. 2262-2266, 2005.

[40] P. Sajo, N. Anthony, S. T. Chiang, and R. W. Thompson, "Synthesis of zeolitic mesoporous materials by dry gel conversion under controlled," Journal of Physical Chemistry, vol. 107, pp. 7006-7014, 2003.

[41] S. Naser Azizi, A. Alavi Daghigh, and M. Abrishamkar, "Phase transformation of zeolite P to Y and analcime zeolites," Journal of Spectroscopy, vol. 2013, Article ID 428216, 5 pages, 2013.

[42] Tuel, D. Farrussenga, and Alain, "Perspectives on zeoliteencapsulated metal nanoparticles and their applications in catalysis," New Journal of Chemistry, vol. 40, pp. 3933-3949, 2016.

[43] Y. Yuanyuan, Z. Haibo, W. Tinghai, and B. Xiaojun, "Green fabrication of hierarchical zeolites from natural minerals," Natl Sci Rev, vol. 7, pp. 1632-1634, 2020.

[44] K. Ding, A. Corma, J. A. Maciá-Agulló et al., "Constructing hierarchical porous zeolites via kinetic regulation," Journal of the American Chemical Society, vol. 137, pp. 11238-11241, 2015.

[45] L. Magdalena, Synthesis, Characterization and Properties of Zeolite Films and Membranes, Lulea University of technology, Luleå, Sweden, 2001.

[46] E. Ghadamnan, S. R. Nabavi, and M. Abbas, "Nano LTA zeolite in water softening process: synthesis, characterization, kinetic studies and process optimization by response surface methodology (RSM)," Journal of Water Environment and Nanotechnology, vol. 4, pp. 119-128, 2019.

[47] K. Margeta, N. Z. Logar, M. Šiljeg, and A. Farkaš, "Natural zeolites in water treatment. s.l.: world's largest science," Technology \& Medicine Open Access book publisher, vol. 81, 2013.

[48] T. S. Jamil, H. S. Ibrahim, I. H. Abd El-Maksoud, and S. T. ElWakeel, "Application of zeolite prepared from Egyptian kaolin for removal of heavy metals: I. Optimum conditions," Desalination, vol. 258, no. 1-3, pp. 34-40, 2010.

[49] Y. Li, L. Li, and J. Yu, "Applications of zeolites in sustainable chemistry,” Inside Cosmetics, vol. 3, no. 6, pp. 928-949, 2017.

[50] K. Hui, C. Chao, and S. Kot, "Removal of mixed heavy metal ions in wastewater by zeolite $4 \mathrm{~A}$ and residual products from recycled coal fly ash," Journal of Hazardous Materials, vol. 127, no. 1-3, pp. 89-101, 2005.

[51] O. Nazarenko and R. Zarubina, "Application of sakhaptinsk zeolite for improving the quality of ground water," Energy and Environmental Engineering, vol. 1, no. 2, pp. 68-73, 2013.

[52] S. K. Pitcher, R. C. T. Slade, and N. I. Ward, "Heavy metal removal from motorway stormwater using zeolites," The Science of the Total Environment, vol. 334-335, pp. 161-166, 2004.

[53] C. Hammond, D. Padovan, G. Tarantino, and R. Soc, "Porous metallosilicates for heterogeneous, liquid-phase catalysis," Open Sci., vol. 5, pp. 1-25, 2018.

[54] N. Fattahi, "Zeolite-based catalysts: a valuable Approach toward ester bond formation," vol. 9, pp. 1-23, 2019.

[55] L. Corma, L. Lichen, and C. Avelino, "Evolution of isolated atoms and clusters in catalysis," Trends in Chemistry, vol. 2, pp. 383-400, 2020.

[56] B. Risheng, S. Yue, L. Yi, and Y. Jihong, "Creating Hierarchical pores in zeolites catalyst," Trends in Chemistry, vol. 1, pp. 601-611, 2019.

[57] H. N. Tran, P. V. Viet, and H.-P. Chao, "Surfactant modified zeolite as amphiphilic and dual-electronic adsorbent for removal of cationic and oxyanionic metal ions and organic compounds," Ecotoxicology and Environmental Safety, vol. 147, pp. 55-63, 2018. 
[58] A. Bauer and G. Berge, "Kaolinite and Smectite dissolution rate in high molar $\mathrm{KOH}$ solutions at 358 and 808C," Applied Geochemistry, vol. 17, pp. 905-916, 1997.

[59] L. Wolfgang, "Zeolite Y: synthesis, modification, and properties-a case revisite," Advances in Materials Science and Engineering, vol. 2014, Article ID 724248, 19 pages, 2014.

[60] E. Ajenifuja, O. O. Akinwunmi, M. K. Bakare, J. A. Ajao, I. F. Adeniyi, and E. O. B. Ajayi, "Remediation of polluted water using natural zeolitic aluminosilicates/lateritic clay ceramic matrix membrane," ISRN Ceramics, vol. 2012, pp. 1-11, 2012.

[61] H. Figueiredo and C. Quintelas, "Tailored zeolites for the removal of metal oxyanions: o," Journal of Hazardous Materials, vol. 274, pp. 287-299, 2014.

[62] S. Jiahui, Y. Zixuan, D. Hongliang, L. Xiwu, P. Lihong, and T. Xiangyi, "Reparation and application of modified zeolites as adsorbents in wastewater treatment." Water Science \& Technology, vol. 7, 2017.

[63] J. A. Ippolito, D. D. Tarkalson, and G. A. Lehrsch, "Zeolite soil application method affects inorganic nitrogen, moisture, and corn growth," Soil Science, vol. 176, no. 3, pp. 136-142, 2011.

[64] M. Reháková, S. Čuvanová, M. Dzivák, J. Rimár, and Z. Gaval'ová, "Agricultural and agrochemical uses of natural zeolite of the clinoptilolite type," Current Opinion in Solid State \& Materials Science, vol. 8, no. 6, pp. 397-404, 2004.

[65] F. A. Mumpton and A. Frederick, "La roca magica: uses of natural zeolites in agriculture and industry," Proceedings of the National Academy of Sciences, vol. 96, no. 7, pp. 3463-3470, 1999.

[66] W. Zhijie, C. Alex, and K. Yip, "Advances in the green synthesis of microporous and. Ao Pan," Journal of Catalysts, vol. 274, pp. 1-18, 2019. 